\title{
Structural Health Monitoring of Steel Pipes under Different Boundary Conditions and Choice of Signal Processing Techniques
}

\author{
Rais Ahmad ${ }^{1}$ and Tribikram Kundu ${ }^{2}$ \\ ${ }^{1}$ Department of Civil \& Environmental Engineering, University of Connecticut, Storrs, CT 06269, USA \\ ${ }^{2}$ Department of Civil Engineering \& Engineering Mechanics, University of Arizona, Tucson, AZ 85721, USA
}

Correspondence should be addressed to Rais Ahmad, rahmad@engr.uconn.edu

Received 20 September 2011; Accepted 24 January 2012

Academic Editor: Piervincenzo Rizzo

Copyright (C) 2012 R. Ahmad and T. Kundu. This is an open access article distributed under the Creative Commons Attribution License, which permits unrestricted use, distribution, and reproduction in any medium, provided the original work is properly cited.

\begin{abstract}
Guided wave technique is an efficient method for monitoring structural integrity by detecting and forecasting possible damages in distributed pipe networks. Efficient detection depends on appropriate selection of guided wave modes as well as signal processing techniques. Fourier analysis and wavelet analysis are two popular signal processing techniques that provide a flexible set of tools for solving various fundamental problems in science and engineering. In this paper, effective ways of using Fourier and Wavelet analyses on guided wave signals for detecting defects in steel pipes are discussed for different boundary conditions. This research investigates the effectiveness of Fourier transforms and Wavelet analysis in detecting defects in steel pipes. Cylindrical Guided waves are generated by piezo-electric transducers and propagated through the pipe wall boundaries in a pitch-catch system. Fourier transforms of received signals give information regarding the propagating guided wave modes which helps in detecting defects by selecting appropriate modes that are affected by the presence of defects. Continuous wavelet coefficients are found to be sensitive to defects. Several types of mother wavelet functions such as Daubechies, Symlet, and Meyer have been used for the continuous wavelet transform to investigate the most suitable wavelet function for defect detection. This research also investigates the effect of different boundary conditions on wavelet transforms for different mother wavelet functions.
\end{abstract}

\section{Introduction}

Early forecasting of the degradation process caused by adverse environmental effects or mechanical damages in pipe network systems can avoid many catastrophic accidents. Now a days, the detection of the existing defects in pipes is one of the major challenges for the structural health monitoring of pipes. Propagation of cylindrical guided waves through pipes for damage detection is becoming an increasingly popular technique for pipe inspection.

Gazis $[1,2]$ first analytically solved the propagation of harmonic waves in an infinitely long elastic hollow cylinder. Many investigators [3,4] used guided wave modes for detecting wall thinning defects in cylindrical pipes. Rose and coworkers $[5,6]$ designed a special probe which can be used both as a transmitter and a receiver during the pipe inspection. Guo and Kundu [7, 8] designed a new transducer holder mechanism for pipe inspection using cylindrical guided waves. Using those transducer holders $\mathrm{Na}$ et al. $[9,10]$ generated cylindrical guided waves for detecting delaminations between steel bars and concrete interface. Ahmad and Kundu [11] investigated the influence of water flow on pipelines using guided wave techniques.

Successful damage detection requires not only the appropriate guided wave modes but also proper use of signal processing techniques or tools. In recent years, wavelet analysis has become a popular technique for processing received signals with time-varying spectra. Many investigators have used the wavelet analysis to characterize damages in materials. Cho et al. [12] discussed the detection of subsurface lateral defects using wavelet transform on propagating Lamb waves. Rioul and Vetterli [13] and Abbate et al. [14] used wavelet transform for processing signals with nonstationary spectral contents. Kaya et al. [15] used wavelet decomposition to detect flaws in stainless steel samples. Ahmad et al. $[16,17]$ used daubechies wavelet transforms for detecting defects in 
free and embedded pipes. Ahmad and Kundu [18] also used continuous wavelet transforms with different wave functions on cylindrical guided wave signals to identify defects in pipes under different boundary conditions.

Gabor transform can be used as another form of wavelet analysis. Gabor [19] adapted the Fourier transform to analyze only a small section of the signal at a time-a technique called windowing of the signal. Bastiaans [2022] related the Gabor expansion and the short-time Fourier transform. Bastiaans introduced the sampled short time Fourier transform to compute the Gabor coefficients and successfully derived a closed form Gaussian function.

Murase and Kawashima [23] tried out different wavelet transforms and showed that when Gabor functions are used as mother wavelets then one can plot group velocity curves for a thin aluminum plate. Ahmad and Kundu [24] also used the Gabor wavelet transform to plot group velocities for defective and defect-free cylindrical pipes from experimental data. Ahmad et al. [25] used daubechies mother wavelet functions to identify defects in transmission pipes.

\section{Theory}

A wavelet is described by the function $\psi_{a, b}(t)$, which is obtained by dilation and translation of a function $\psi(t)$ as defined by:

$$
\psi_{a, b}(t)=\frac{1}{|\sqrt{a}|} \psi\left(\frac{t-b}{a}\right) ; \quad \text { with } a>0, b \in \mathfrak{R},
$$

where $\mathfrak{R}$ is the set of real numbers. The function $\psi_{a, b}$ is called mother wavelet. The parameter $a$ represents the scale index, and $b$ indicates the time shifting or translation. The approximation of a function $f(t)$ by wavelets is carried out using the coefficients $C$ given by:

$$
C(a, b)=\left\langle f ; \psi_{a, b}\right\rangle,
$$

where $\langle * ; *\rangle$ defines the scalar product.

The continuous wavelet transform or CWT is given by:

$$
\operatorname{CWT} f(a, b)=\frac{1}{|\sqrt{a}|} \int_{-\infty}^{+\infty} f(t) \psi^{*}\left(\frac{t-b}{a}\right) d t,
$$

where $*$ denotes the complex conjugate of the function.

In simple words, the continuous wavelet transform is defined as the sum over all time of the signal multiplied by scaled, shifted version of the wavelet function, $\psi$ :

$$
C(\text { scale, position })=\int_{-\infty}^{+\infty} f(t) \psi(\text { scale, position, } t) d t \text {. }
$$

The results of the CWT are many wavelet coefficients $C$, which are a function of scale and position. Therefore, wavelet analysis is nothing but the breaking up of a signal into shifted and scaled version of the original mother wavelet.

\section{Experiments}

The primary objective of this research is to investigate how cylindrical guided waves can be used effectively to detect defects in steel pipes under different boundary conditions. In the process, it will be explored how different signal processing techniques like Fourier transform and continuous wavelet analysis (CWA) influence the detection process. Fourier transforms will endow with possible propagating modes, and CWA provides scaled coefficients affected by the presence of defects. CWA was performed using Daubechies, Symlet, and Meyer mother wavelet functions on the signals received for both defect free and defective pipes. The pipes were kept under three different boundary conditions: (1) traction-free boundary condition when pipes were kept in open air; (2) when water flows through the pipes, keeping the inner boundary of the pipes in contact with water and outer boundary in open air; (3) the pipes are embedded in soil keeping the outer surface in contact with soil and the inner surface in traction-free boundary condition. Figures 1(a) and 1(b) show the schematic diagrams for different boundary conditions and instrumental arrangements, respectively. Relatively high-frequency $(1 \mathrm{MHz})$ piezoelectric transducers were used as transmitters as well as receivers. The transmitter was activated by a tone-burst excitation using WAVETEK function generator (Model 395) and a MATEC-gated 310 Amplifier for high-frequency excitation. The received signal was amplified by a MATEC 605 amplifier. The signal amplitude was then displayed on an oscilloscope screen as a function of time and frequency. To hold the transducers onto the test specimens, two transducer holders developed by Guo and Kundu [7, 8] were used. Harmonic $1 \mathrm{MHz}$ piezoelectric transducers with a diameter of $13 \mathrm{~mm}$ (0.5 inch) were used for the experiments. Vaseline was used as the couplant.

3.1. Specimens. A specimen set, consisting of three steel pipes, were fabricated. All three pipes were $1200 \mathrm{~mm}(\sim 4 \mathrm{ft})$ long and had $21.4 \mathrm{~mm}$ (13.5/16 inch) outer and $15.6 \mathrm{~mm}$ (10/16 inch) inner diameters. One pipe was defect-free, and the other two had mechanical defects: a gouge and a dent, that were artificially fabricated on the pipe. The gouge anomaly was fabricated by pressing the outer wall of the pipe while keeping the inner diameter unchanged by placing a rigid rod inside. The dent type anomaly was formed by pressing the outer wall, keeping the inner wall free to deform. In both types of defect, the outer walls were cold-pressed. The defect covered a complete $\left(360^{\circ}\right)$ revolution. Table 1 gives dimensions of the pipes and the defects. Table 2 shows the acoustic properties of steel-the pipe material. Properties of the surrounding soil used in this experiment are given in Table 3 .

\section{Results}

Experiments were carried out in three phases for pipes with three boundary conditions. During the experiment, cylindrical guided waves were generated by piezoelectric transducers. Guided waves were generated at one end of the pipe and received at the other end by another receiving transducer in a pitch-catch configuration. The received 
TABle 1: Different types of pipe defects and their dimensions.

\begin{tabular}{|c|c|c|c|c|c|c|}
\hline \multirow{2}{*}{ Type } & \multirow{2}{*}{ Pipe length (mm) } & \multicolumn{2}{|c|}{ Diameter } & \multirow{2}{*}{ Thickness (mm) } & \multicolumn{2}{|c|}{ Damage dimension } \\
\hline & & Outer $(\mathrm{mm})$ & Inner (mm) & & $\begin{array}{c}\text { Depth }(\mathrm{mm}) \text { (percentage of } \\
\text { thickness) }\end{array}$ & Width/diameter $(\mathrm{mm})$ \\
\hline $\begin{array}{l}\text { Defect-free } \\
\text { (pipe A) }\end{array}$ & 1200 & 21.4 & 15.6 & 2.9 & - & - \\
\hline Gouge (pipe B) & 1200 & 21.4 & 15.6 & 2.9 & $1.26(43.4 \%)$ & 5.92 \\
\hline Dent (pipe C) & 1200 & 21.4 & 15.6 & 2.9 & $1.41(48.6 \%)$ & 5.21 \\
\hline
\end{tabular}

TABLE 2: Acoustic properties of steel.

\begin{tabular}{lcc}
\hline P-wave speed $(\mathrm{km} / \mathrm{s})$ & S-wave speed $(\mathrm{km} / \mathrm{s})$ & Density $(\mathrm{gm} / \mathrm{cc})$ \\
\hline 5.96 & 3.26 & 7.932 \\
\hline
\end{tabular}

TABLe 3: Soil properties.

(1) coefficient of uniformity, $C_{U}=5.0$

(2) coefficient of concavity, $C_{C}=0.8$

(3) moisture content $=0.58 \%$

(4) compressional wave velocity, $C_{p} \sim 220 \mathrm{~m} / \mathrm{s}$. [23, 26]

(5) shear wave velocity, $C_{s} \sim 140 \mathrm{~m} / \mathrm{s}$. $[24,26]$

signals were in the form of $V(f)$ curves (i.e., amplitude versus frequency) and time series (amplitude versus time).

The effect of different signal processing techniques for detecting defects in pipes was then investigated. Two separate signal processing techniques were used:

(a) the first segment used experimental $V(f)$ curves to identify the propagating modes through the pipes;

(b) the next segment applied continuous wavelet analysis (CWA) on experimental time series signals, using different types of mother wavelet functions to investigate which mother functions are more effective in identifying defects in pipes for all three boundary conditions.

Effects of these signal processing techniques are discussed in the following sections.

4.1. Experimental $V(f)$ Curves and Identification of Propagating Modes. In this section, the sensitivity of pipe defects on the propagating guided wave modes is investigated under different boundary conditions. Generation of guided waves in pipes is very sensitive to the incident angle of the transducers. The first challenge is to find the appropriate incident angles for which strong guided waves can be generated. The incident angles of the transmitter were adjusted experimentally to obtain strong signals. The incident angles $(\Phi)$ of $28^{\circ}$ and $57^{\circ}$ were found to produce strong guided wave signals. The $57^{\circ}$ inclination angle produced the strongest signal and used in this paper to construct the $V(f)$ curves.

4.1.1. Traction-Free Boundary Condition. Figure 2(a) shows the experimental $V(f)$ curves for an incident angle of $57^{\circ}$ when the pipes were kept in open air with traction-free boundary condition. As expected, defect-free pipe produced stronger signals than the defective pipes (Figure 2(a)). Theoretical phase velocity dispersion curves for a cylindrical pipe were plotted using the geometric and material properties of pipes given in Tables 2 and 3 using DISPERSE software. In order to identify the propagating guided wave modes through the defective and defect-free pipes, phase velocities are calculated from the peaks in the experimental $V(f)$ curves using Snell's law $\left[v_{\mathrm{ph}}=v_{c} / \operatorname{Sin} \theta_{c}\right]$.

Figure 2(b) shows theoretical phase velocity dispersion curves for a cylindrical pipe (defect-free), where both longitudinal and flexural modes are plotted. For the defect free signal, phase velocities were calculated for peaks at 380, 1020, and $1140 \mathrm{kHz}$ plotted in Figure 2(b). The phase velocity corresponding to the peak at $380 \mathrm{kHz}$ matches closely with the theoretical $F(1,2)$ mode. Peaks at 1020 and $1140 \mathrm{kHz}$ match closely with $F(1,2), L(0,2)$, and $F(1,3)$ modes for the defect-free pipe. This means that the peaks at 1020 and $1140 \mathrm{kHz}$ represent propagating modes $L(0,2)$, $F(1,2)$, or $F(1,3)$, or all of them together. For the defect-free pipe, the strongest peak occurs at $1140 \mathrm{kHz}$ which means that the strongest propagating modes could be $F(1,2), L(0,2)$ or $F(1,3)$. For the gouged pipe, the peaks could be selected at 580,700 , and $1180 \mathrm{kHz}$ (Figure 2(a)), and the corresponding guided wave modes can be identified as $F(1,2), L(0,2)$, and $F(1,3)$ (Figure 2(b)). The strong peak at $700 \mathrm{kHz}$ for the gouged pipe corresponds to the $F(1,2)$ propagating mode. For the dent pipe, the peaks are observed at 660 and $1300 \mathrm{kHz}$ that again correspond to $F(1,2), L(0,2)$, and $F(1,3)$ modes. The stronger peak at $660 \mathrm{kHz}$ represents $F(1,2)$ mode for the dent pipe. From this investigation, it can be observed that for the traction-free boundary condition, stronger $F(1,2)$, $L(0,2)$ and $F(1,3)$ modes propagate for the defect-free pipe and for the gouged and dented pipes, strong $F(1,2)$ mode and weak $F(1,3)$ and $L(0,2)$ modes may propagate.

4.1.2. Pipes with Water Flow. Figure 3(a) shows experimental $V(f)$ curves obtained for both defect-free and defective pipes when water flows through the pipes when the incident angle is $57^{\circ}$. In this condition, the strength of the signal for the defect-free pipe is stronger than the defective pipes. It can be observed that the strength of the signals (Figure $3(\mathrm{a})$ ) is weaker than that obtained for the traction-free condition (Figure 2(a)). Presence of flowing water reduces the strength of the signals implying that a part of the ultrasonic energy is leaked into the water and does not reach the receiving transducer. Theoretical phase velocity dispersion curves are plotted in Figure 3(b) for the condition when water flows 


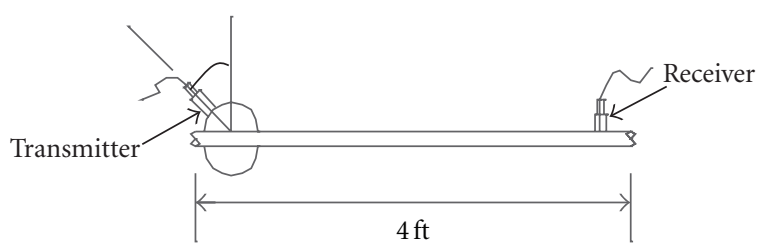

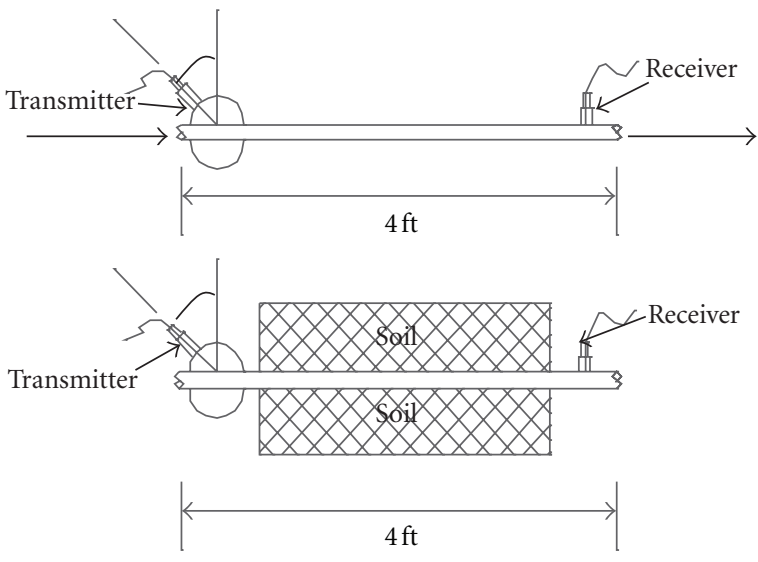

(a)

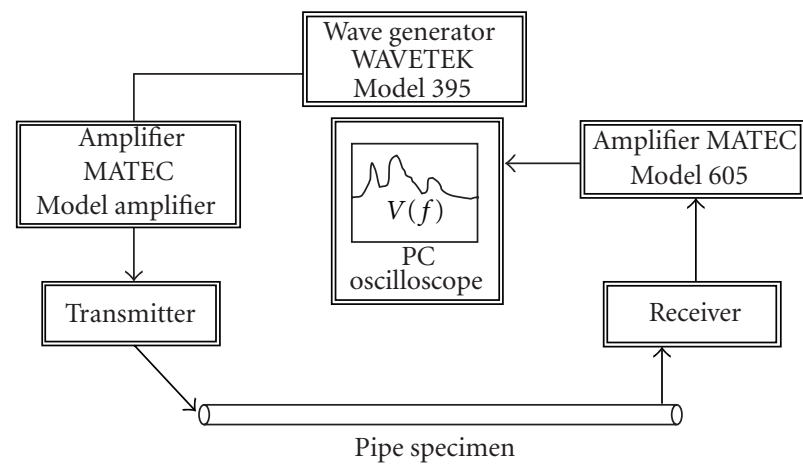

(b)

FIgURE 1: (a) experimental setup (i) pipe in traction-free boundary condition, (ii) when water flows through the pipes, and (iii) pipes embedded in soil. (b) schematic diagram of the instrumental arrangement.

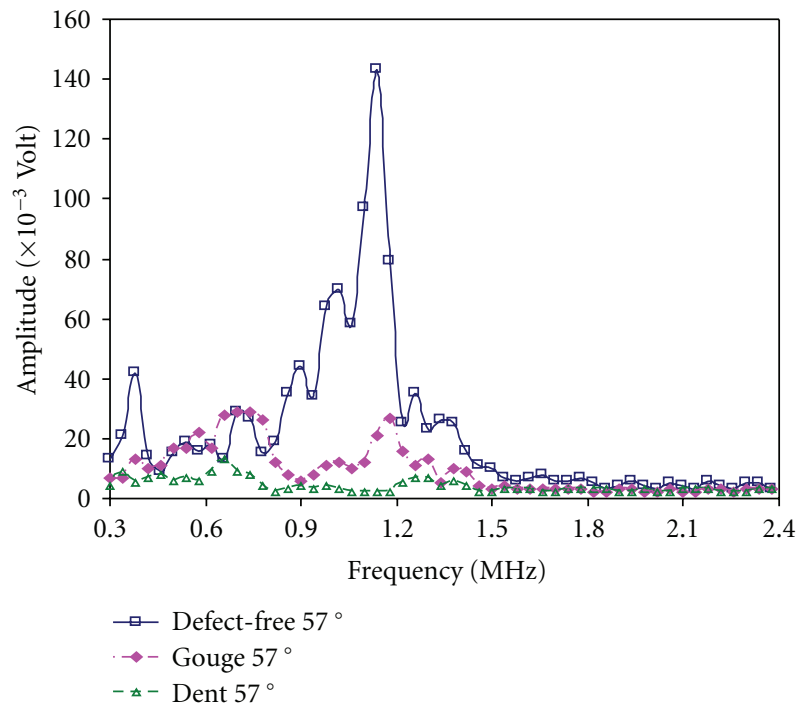

(a)

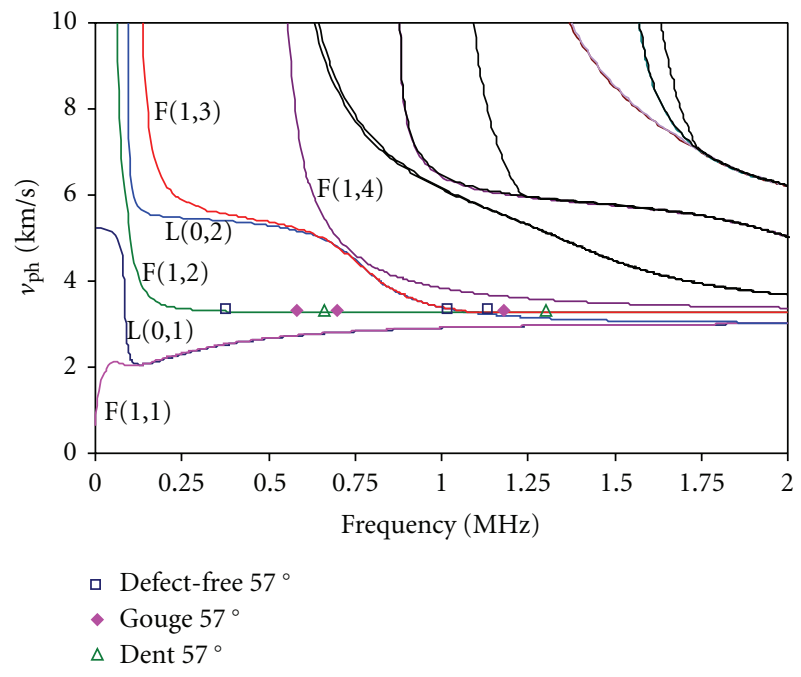

(b)

Figure 2: (a) experimental $V(f)$ curves for defect-free and defective pipes for traction-free boundary condition for $57^{\circ}$ incident angle for defective and defect free pipes (b) theoretical phase velocity dispersion curves obtained for a steel pipe with experimentally obtained phase velocities for modes generating at $57^{\circ}$ incident angle.

through the pipes. A conceptual sink is placed at the center of the pipe for plotting phase velocity dispersion curves. Due to the presence of water, $L(0,1)$ and $F(1,1)$ are absent from the theoretical phase velocities. From the experimental $V(f)$ curves shown in Figure 3(a), peaks are selected for calculating the phase velocities to identify the propagating modes. For the defect-free pipe, the selected peaks are at 580,
1100 , and $1140 \mathrm{kHz}$. The peak at $580 \mathrm{kHz}$ corresponds to $F(1,2)$ mode. The stronger peaks at 1100 and $1140 \mathrm{kHz}$ most likely correspond to $F(1,2)$ and $F(1,3)$ modes, respectively. For the gouged pipe, peaks which are weaker than the defectfree pipe are selected at 620 and $1220 \mathrm{kHz}$. The possible propagating modes can be $F(1,2)$ or $F(1,3)$. For the dented pipe, the major peaks occur at 500 and $1180 \mathrm{kHz}$ which 


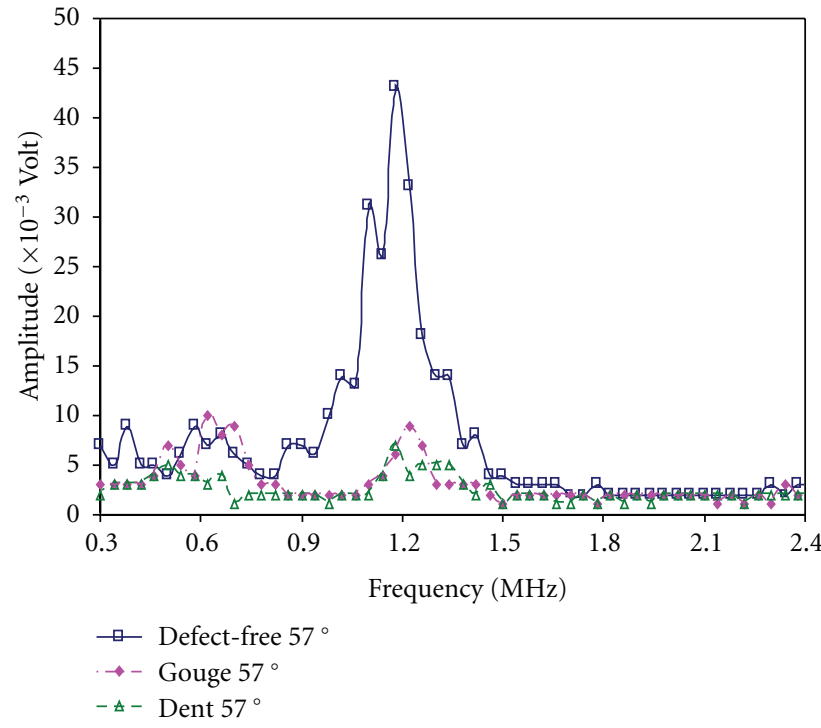

(a)

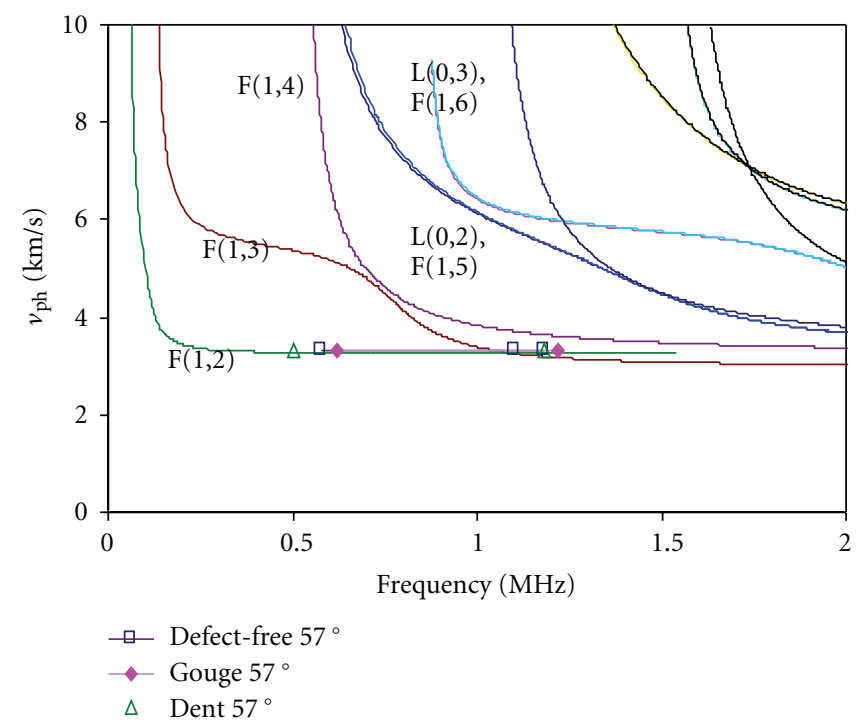

(b)

FIgURE 3: (a) experimental $V(f)$ curves for defect-free and defective pipes when water flows through the pipes at $57^{\circ}$ incident angle for defective and defect free pipes, (b) theoretical phase velocity dispersion curves obtained for a steel pipe with experimentally obtained phase velocities for modes generating at $57^{\circ}$ incident angle.

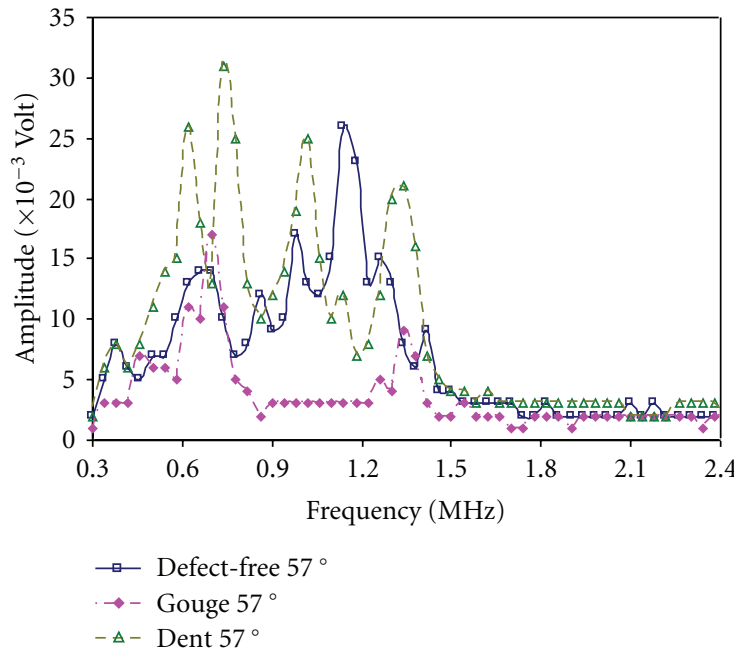

(a)

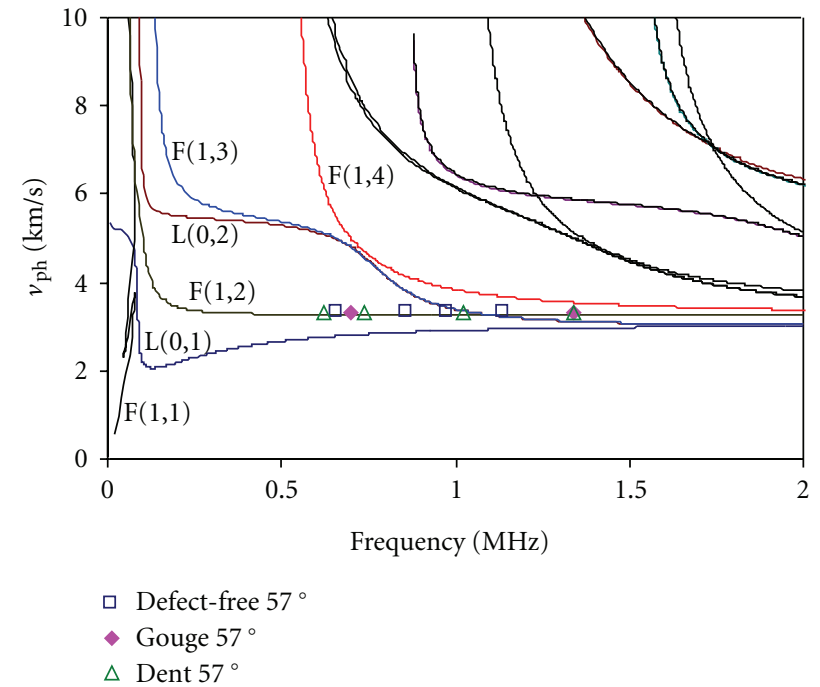

(b)

FIGURE 4: (a) experimental $V(f)$ curves for defect-free and defective pipes when pipes are embedded in soil for $57^{\circ}$ incident angle for defective and defect free pipes (b) theoretical phase velocity dispersion curves obtained for a steel pipe with experimentally obtained phase velocities for modes generating at $57^{\circ}$ incident angle.

corresponds to $F(1,2)$ and/or $F(1,3)$ mode. In summary, it can be stated that when water flows through the pipes strong $F(1,2)$ and $F(1,3)$ modes propagate through the wall of the defect-free pipe at slightly higher frequency $(>1000 \mathrm{kHz})$. For the gouged pipe, the possible propagating modes are weak $F(1,2)$ and $F(1,3)$. For the dented pipe, the possible propagating modes are $F(1,2)$ and $F(1,3)$.

4.1.3. Pipes Embedded in Soil. Figure 4(a) shows the experimental $V(f)$ curves, when the pipes are embedded in soil.
The soil properties are given in Table 3. It can be observed that multiple strong and distinct peaks which referred to as propagating guided wave modes are generated for both the defective and defect free pipes. It is interesting to note that the strengths of the signals are similar for both defectfree and defective pipes. Due to the presence of surrounding soil, the overall strength of the signal is reduced compared to the signal strengths in cases of traction-free boundaries. The dented pipe produces stronger and distinct peaks at $620,740,1020$, and $1340 \mathrm{kHz}$. The 620 and $740 \mathrm{kHz}$ peaks 
match with the $F(1,2)$ mode in Figure $4(\mathrm{~b})$. The peaks at 1020 and $1340 \mathrm{kHz}$ represent either $F(1,2), L(0,2)$, or $F(1,3)$ mode. These peaks are strong. In previous cases (Sections 4.1 and 4.2), the experimental $V(f)$ curve for the dented pipe produced weaker peaks which means generation of weaker propagating modes. Clearly, the propagating modes decay before traveling long distances when the dented pipe is kept in the open air with water flow or no-flow condition. When the pipe is buried under soil, distinct propagating modes are generated that can travel a longer distance. For buried dented pipes, more modes are generated that are very sensitive to defects.

For the defect-free pipe, peaks are observed at 660, 860, 980, and $1140 \mathrm{kHz}$. Peaks at 660 and $860 \mathrm{kHz}$ represent $F(1,2)$ mode. Peaks at 980 and $1140 \mathrm{kHz}$ represent possible $F(1,2), L(0,2)$, or $F(1,3)$ mode. For the gouged pipe, peaks are generated at 700 and $1340 \mathrm{kHz}$. These peaks correspond to $F(1,2), L(0,2)$, or $F(1,3)$ mode. It should be noted that for the defective pipes like dented and gouged, stronger peaks are obtained at a lower frequency $(<1000 \mathrm{kHz})$ which refers to the $F(1,2)$ mode. It implies that for pipes embedded in soil, strong guided wave modes can be generated at low frequencies which would be efficient in detecting defects.

\subsection{Continuous Wavelet Transform (CWT) with Different} Mother Functions. This section investigates the effectiveness of continuous wavelet transforms (CWTs) as a signal processing tool in assessing the integrity of pipes for the three stated boundary conditions. CWT has a broad spectrum and is associated with proper choice of mother wave function and appropriate scaling. Wavelet analysis produces a timescale view of a signal that has a scale aspect and a time aspect. Scaling a wavelet means stretching it. The smaller the scale factor, the more compressed the wavelet; while higher scales correspond to the more stretched wavelets. In this section, CWTs are performed on experimental timeseries signals obtained for the 3 sets of boundary conditions. To efficiently use CWT as a signal processing tool for health monitoring, it is important to select appropriate mother function with proper scaling which will facilitate the integrity assessment. In Section 4.2.1, the range of scaling on different mother functions is investigated in order to identify appropriate scale for different types of mother wavelet functions. The time series signals were associated with significant amount of white noise. Using wavelets, noise from the signals are removed by identifying which component or components contain the noise. The signals are then reconstructed omitting those components. The one dimensional model for a noisy signal is basically of the form:

$$
s(n)=f(n)+\sigma e(n),
$$

where time $n$ is equally spaced, $e(n)$ is a Gaussian white noise $N(0,1)$, and noise level $\sigma$ is equal to 1 . The objective of denoising is to suppress the noise part of the signal $s$ and to recover $f$.

4.2.1. Scaling for Different Wave Functions. Fixing the proper scale for a mother wave function is particularly important for processing a signal. The effectiveness of a CWT depends on the right scaling, which stretches or contracts a wave function. For this investigation, signals received for the defectfree pipe in traction free boundary conditions were used. The wave functions that were used for this investigation are Daubechies (db4), Symlet (sym4), Coiflet (coif2), Gaussian (gauss1), Meyer, and Mexican Hat with scaling of 16, 64 and 256.

Figures 5(a)-5(f) show CWT of the signal for the defectfree pipe in traction-free boundary condition for a scaling of 16. The experimental signals which are associated with significant white noise were denoised before applying CWT. Figures 5(a), 5(b), and 5(c) that used db4, sym4, and coif2 mother functions, respectively produced similar plots which are helpful in identifying the difference between defective and defect-free pipes. For gauss1 (Figure 5(d)) and Mexican Hat (Figure 5(f)), the difference is not clearly visible for a scaling of 16. For Meyer wavelet function, a scale of 16 gives clear distinction between the defect-free and defective pipes. For a scaling of 64 (Figures 6(a)-6(f)), the wave functions, db4, sym4, coif2, gauss1, Meyer, and Mexican Hat do not produce distinct signals which can clearly show the difference. Similarly, for a higher scale of 256 (Figures 7(d), 7(e), and 6(f)), gauss1, Meyer and Mexican Hat do not exhibit distinct differences. The plots produced by db4, sym 4 and coif2 (Figures 7(a), 7(b), and 7(c)) wave functions for a scale of 256 are stretched too long and the difference between the defect-free and defective signals are not so differentiable. From this investigation, it can be concluded that for a lower scale of 16, the CWTs are more effective in assessing the integrity of pipes. It can also be observed that wave functions gauss 1 and Mexican Hat do not provide any significant information about the differences between defective and defect free pipes. It can be said from this investigation that $\mathrm{db} 4$, sym4, coif2, and Meyer wave functions should produce more meaningful results. It may be noted that sym 4 and coif2 functions produce almost similar results as well as plots. In the following, only $\mathrm{db} 4$, sym4, and Meyer wavelet functions with a scaling factor of 16 are used to investigate the integrity of pipes.

\subsubsection{Continuous Wavelet Analysis for Defect Detection of} Pipes under Different Boundary Conditions. The effectiveness of continuous wavelet analysis (CWA) in detecting defects in pipes under different boundary conditions mentioned in the previous section (Section 4.1) is then investigated. Daubechies (db4), Symlet (sym4), and Meyer wave functions were employed with a scaling of 16 for this investigation.

Continuous Wavelet Transform for Traction-Free Boundary Conditions. Figures 8(b), 8(c), and 8(d) show continuous wavelet analyses for defect-free and defective pipes under traction-free boundary conditions using db4, sym4, and Meyer functions, respectively. The signals are associated with significant amount of noise. Using db4 wavelets, noise from the signals is removed by identifying which component or components contain the noise. The signals are then reconstructed omitting those noisy components. Figure 8(a) 


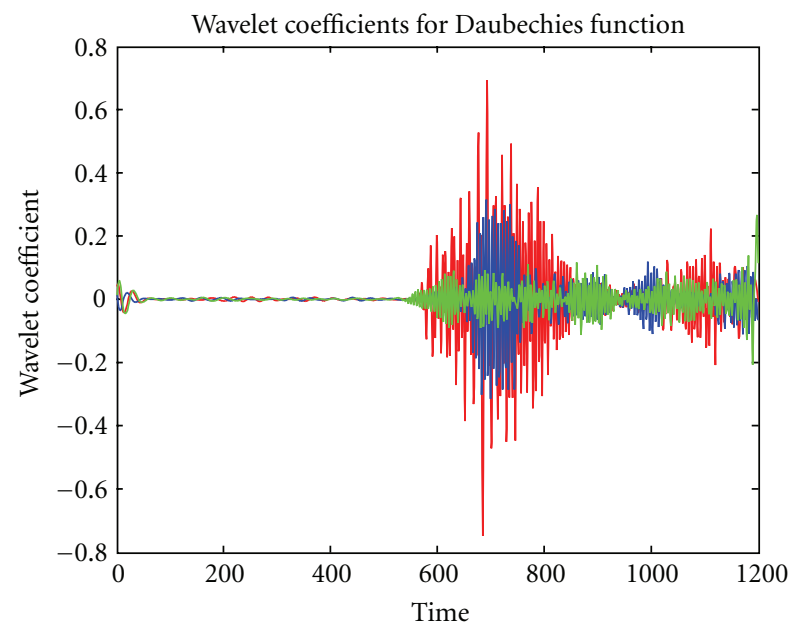

(a)

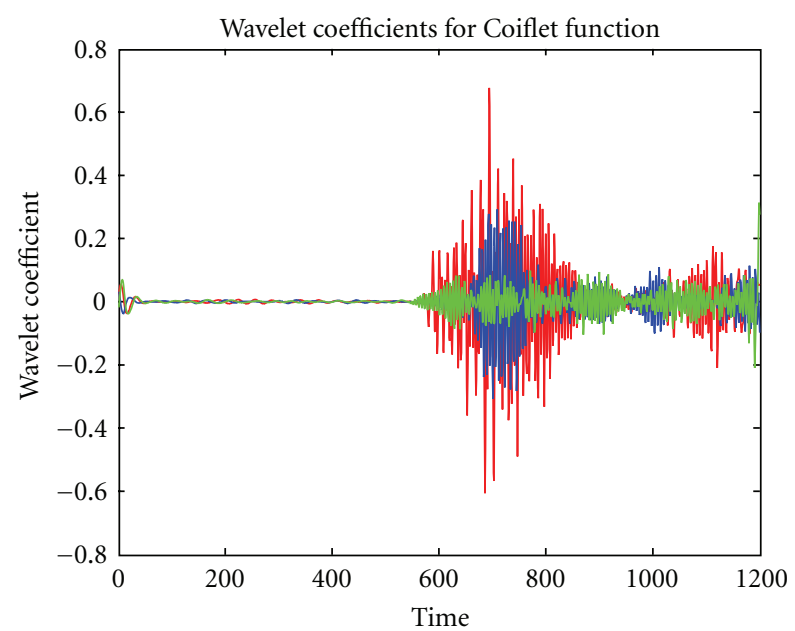

(c)

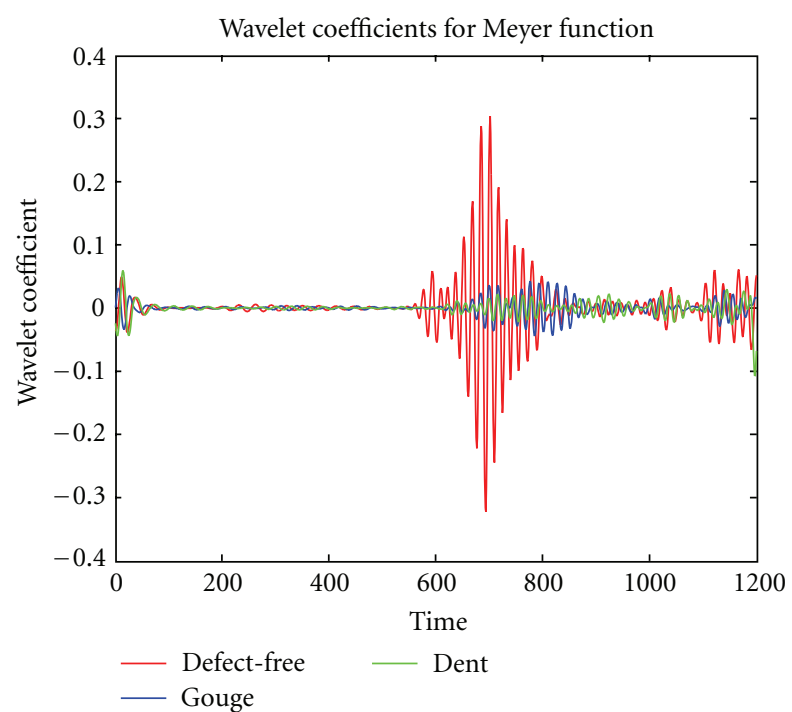

(e)

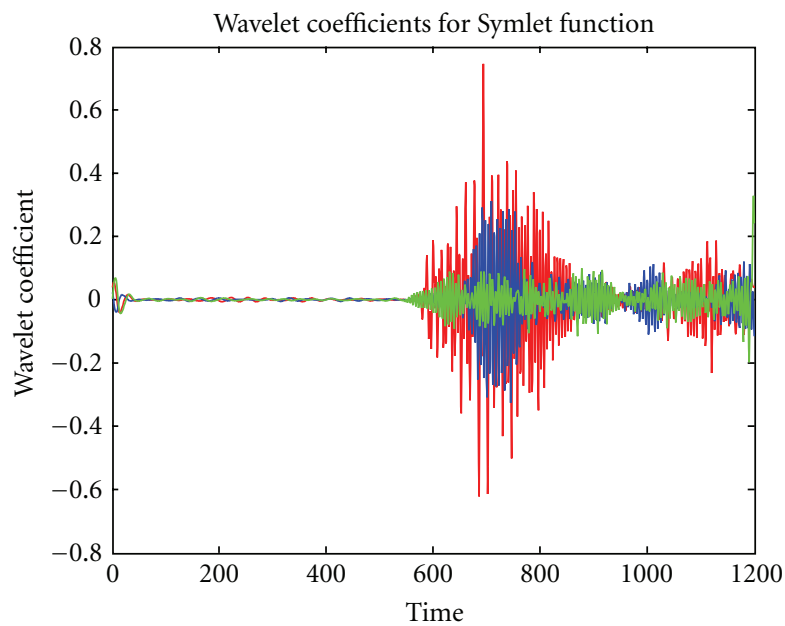

(b)

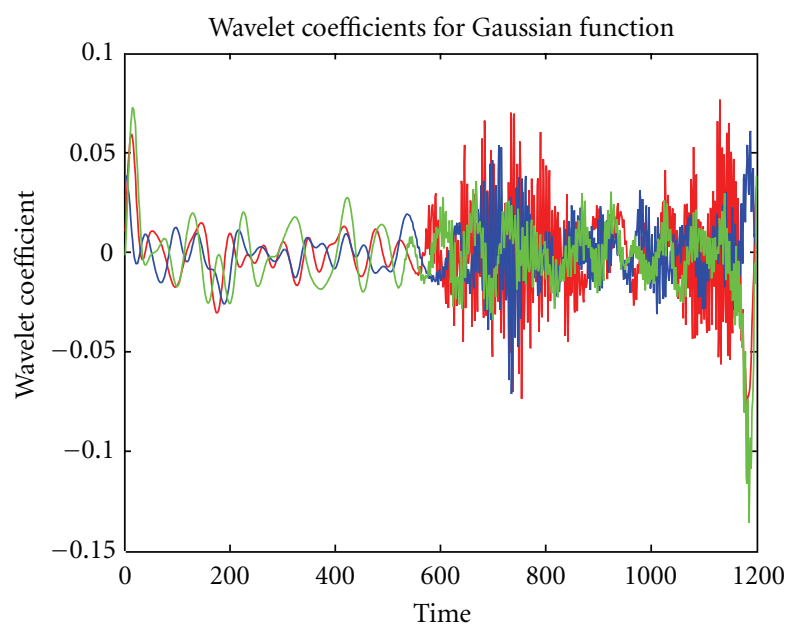

(d)

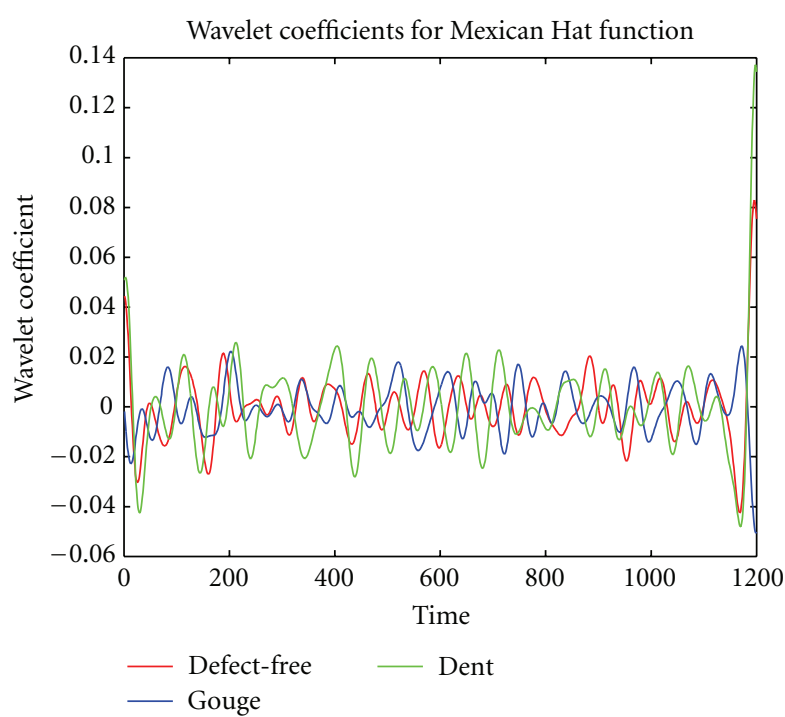

(f)

Figure 5: Comparison of experimental signals for defective and defect-free pipes using different wavelet functions with a scale of 16 for (a) db4, (b) sym4, (c) coif2, (d) gauss1, (e) Meyer, and (f) Mexican hat wavelet functions. 


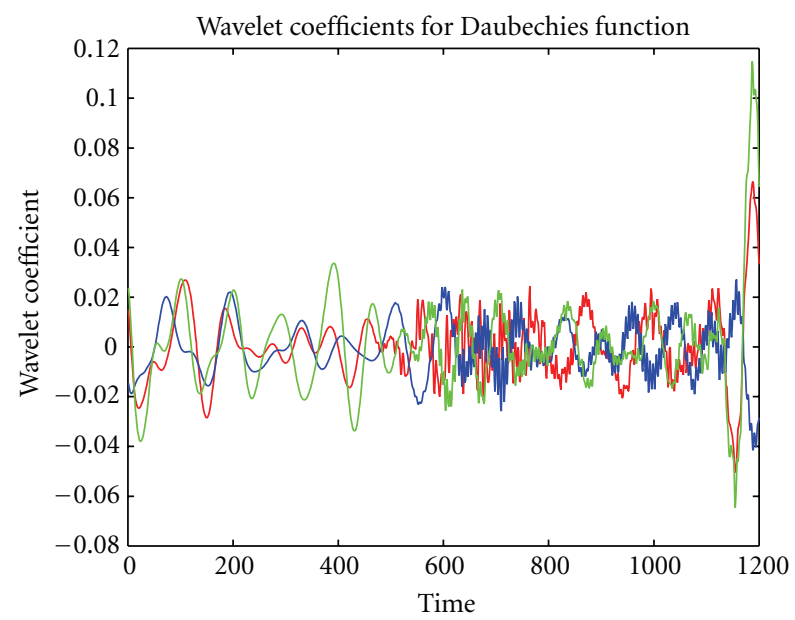

(a)

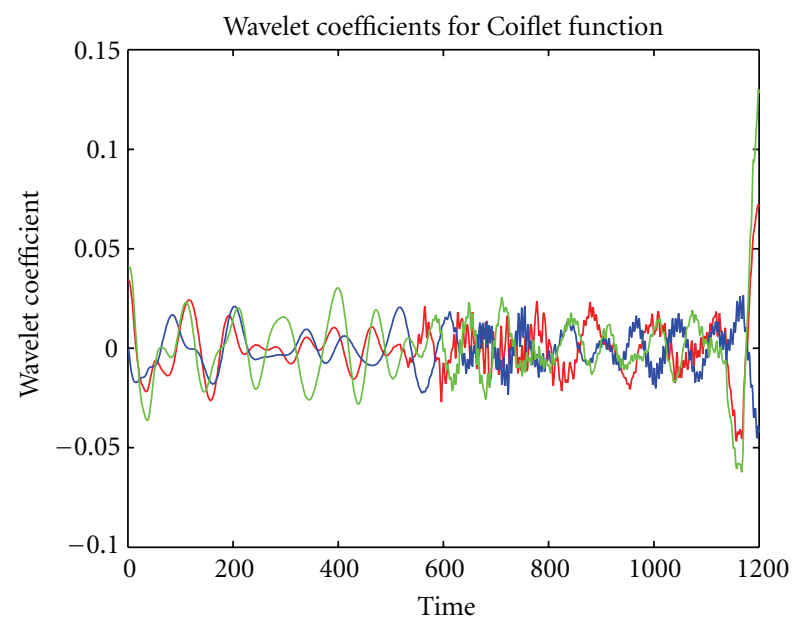

(c)

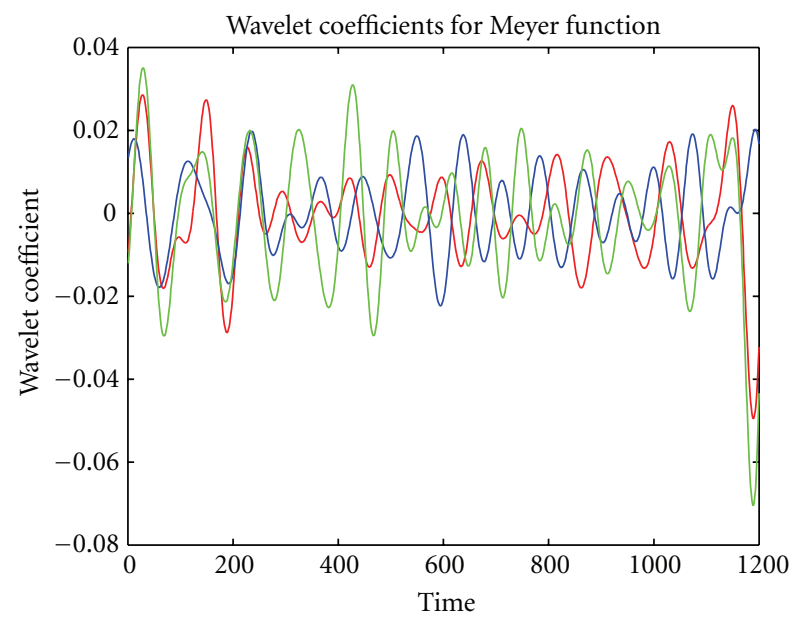

Defect-free
- Gouge

(e)

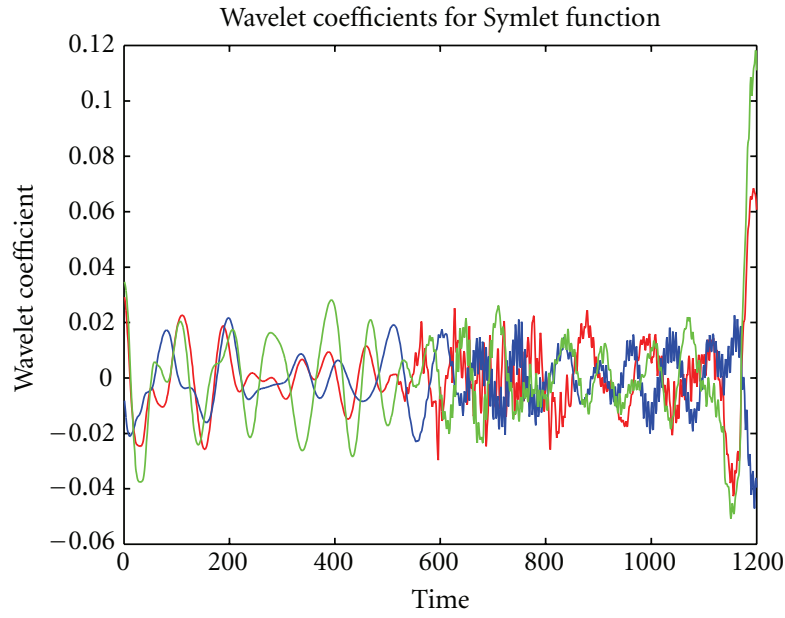

(b)

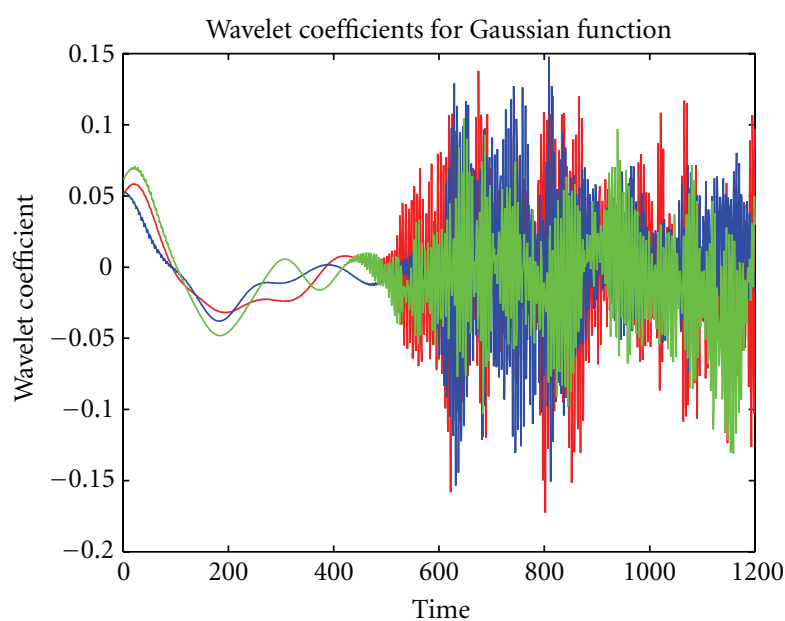

(d)

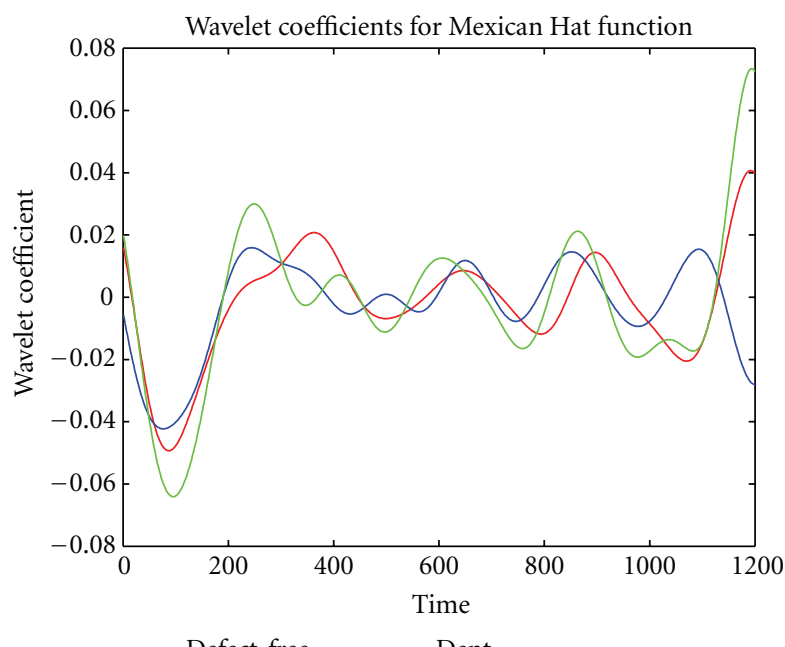

Defect-free
Gouge

(f)

FIgURE 6: Comparison of experimental signals for defective and defect-free pipes using different wavelet functions with a scale of 64 for (a) $\mathrm{db} 4,(\mathrm{~b})$ sym4, (c) coif2, (d) gauss1, (e) Meyer, and (f) Mexican hat wavelet functions. 


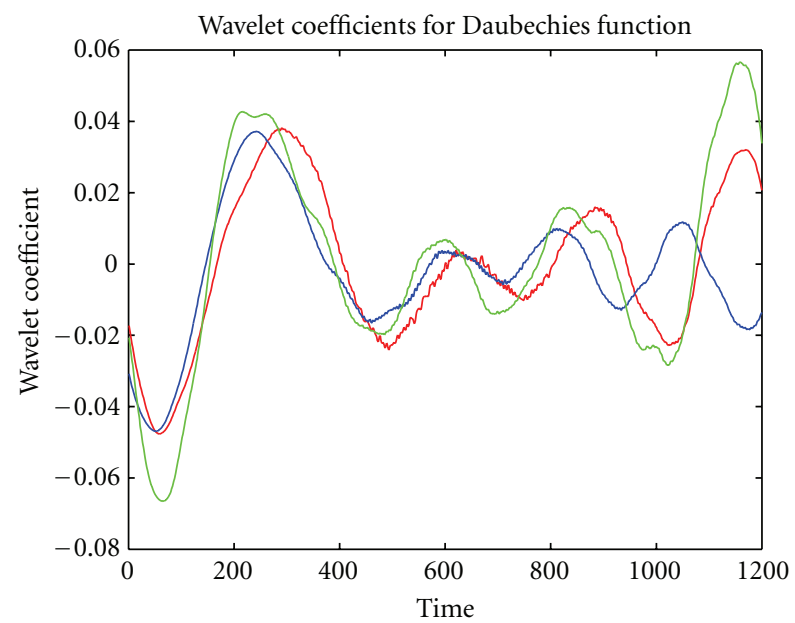

(a)

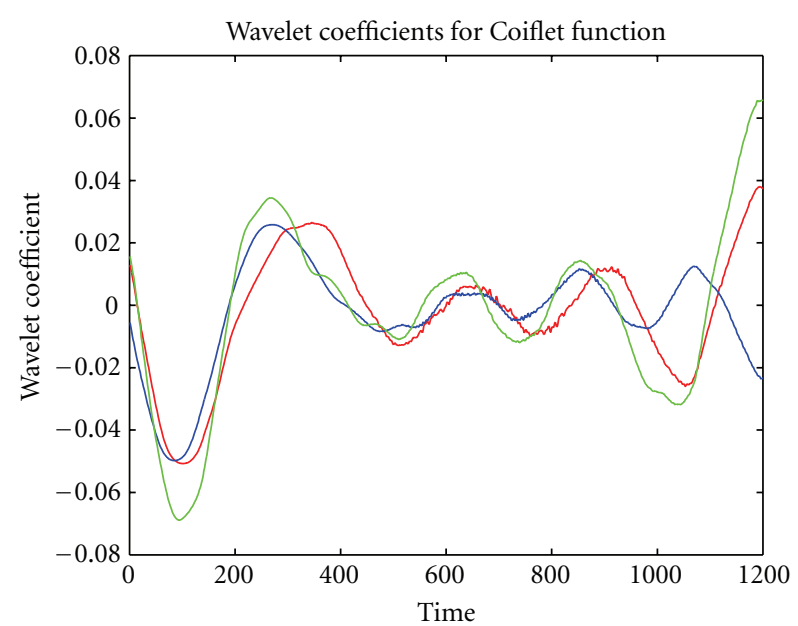

(c)

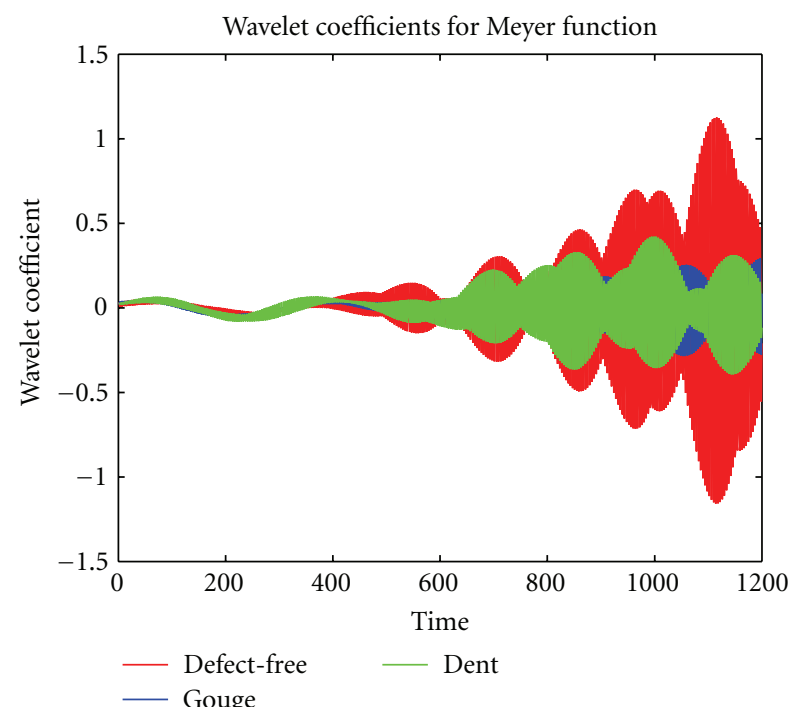

(e)

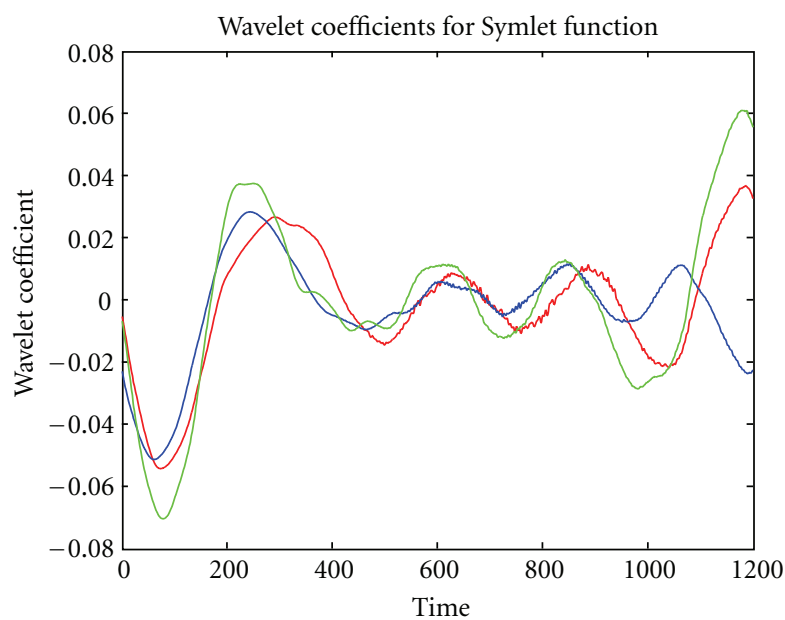

(b)

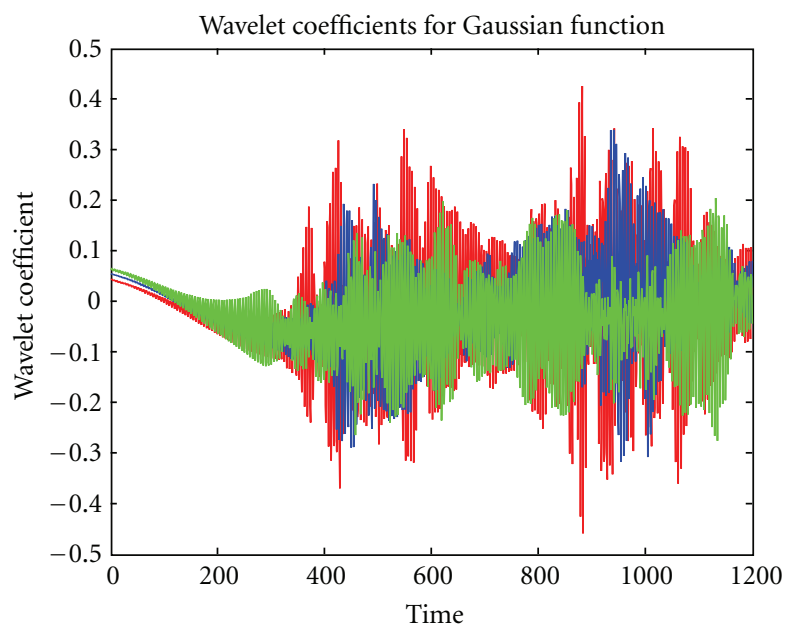

(d)

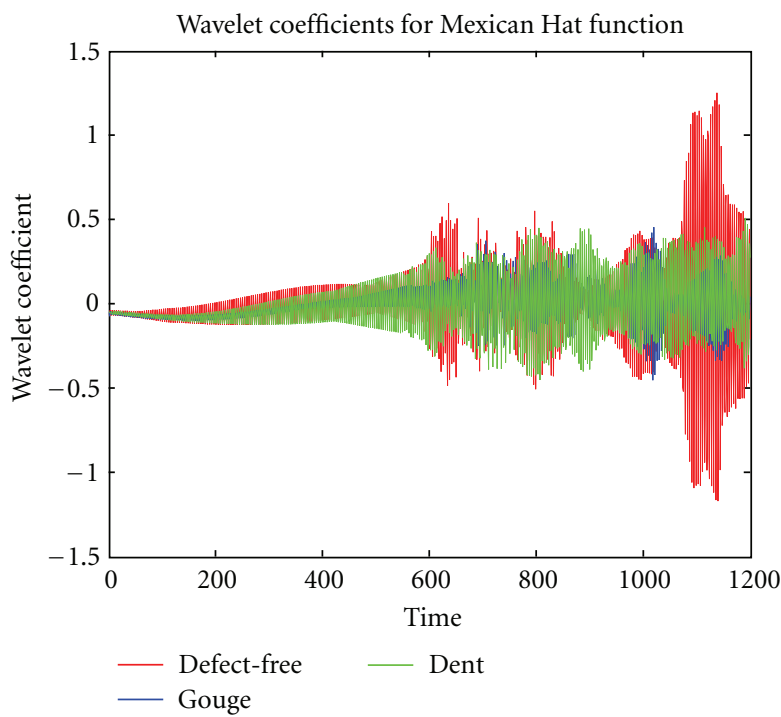

(f)

FIGURE 7: Comparison of experimental signals for defective and defect-free pipes using different wavelet functions with a scale of 256 for (a) db4, (b) sym4, (c) coif2, (d) gauss1, (e) Meyer, and (f) Mexican hat wavelet functions. 

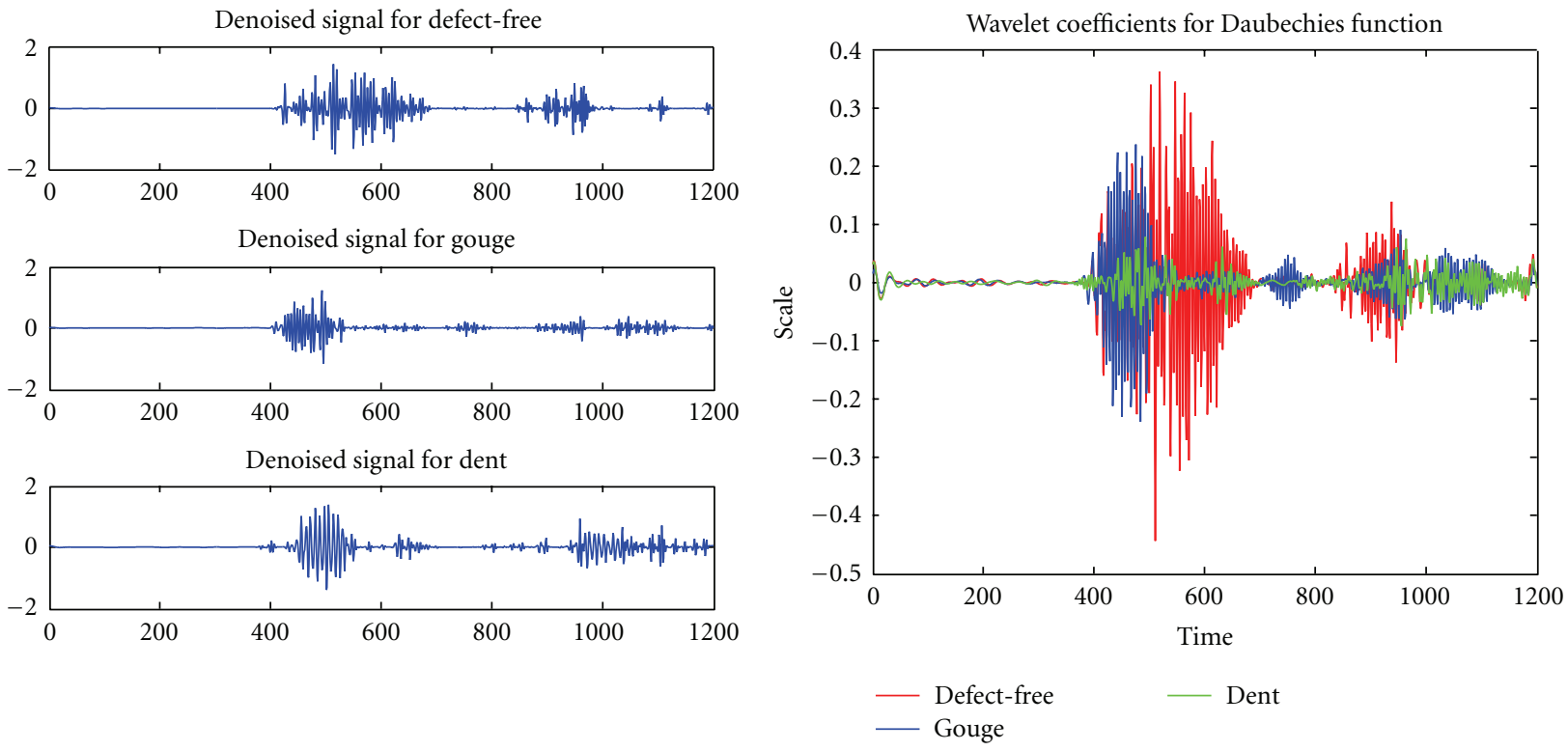

(a)

(b)

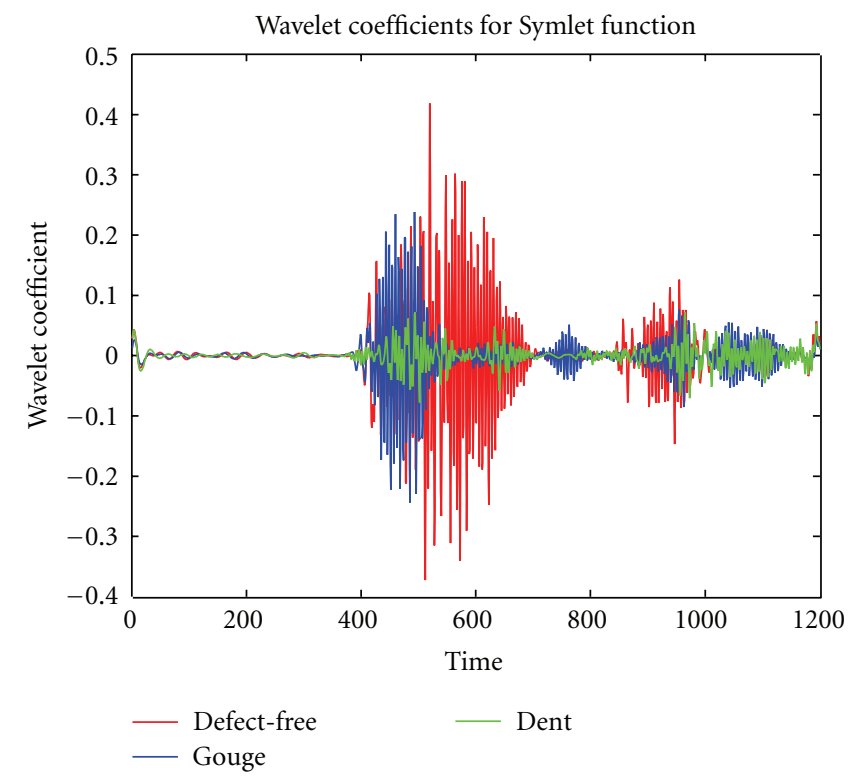

(c)

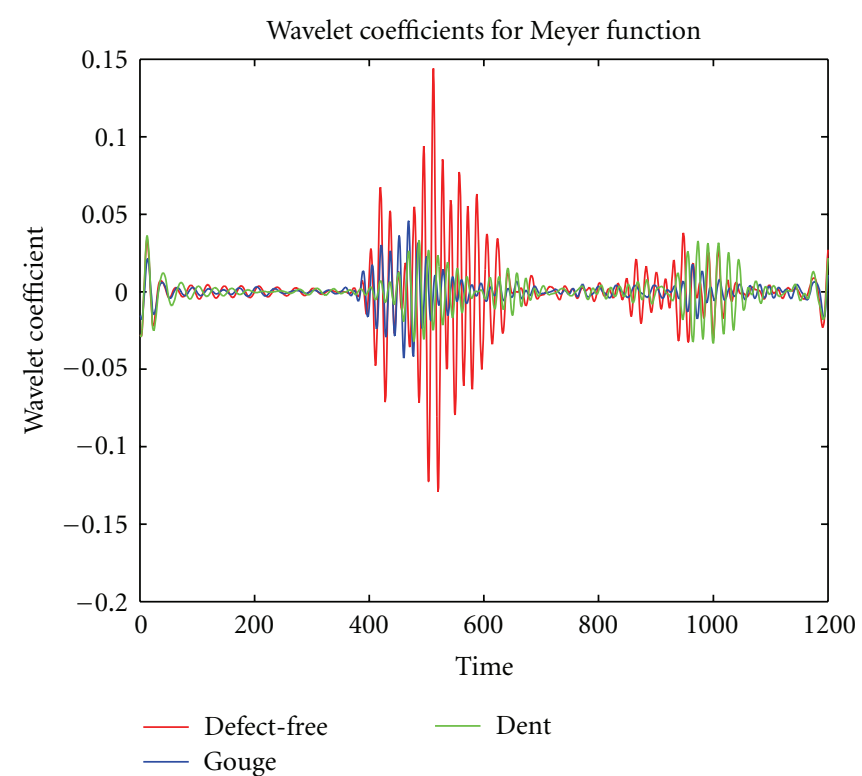

(d)

FIGURE 8: (a) denoised signals for defect-free, gouged, and dent pipes. Continuous wavelet transforms for defect-free, gouged and dented pipes under traction-free boundary conditions, (b) for Daubechies (db4) function, (c) for Symlet (sym4) function, and (d) for Meyer function.

shows the denoised time series signal for the defect-free, gouged, and dented pipes under traction-free boundary conditions. Figures 8(b), 8(c), and 8(d) show the calculated wavelet coefficients with respect to time for $\mathrm{db} 4, \operatorname{sym} 4$, and Meyer functions, respectively. The time scale is shown in 1200 equal divisions, where each division accounts for $7.2 \mathrm{~ns}$ (nano seconds). The time series signal (Figure 8(a)) shows that the first patch of modes appear between 400 and 600 time divisions. When $\mathrm{db} 4$ and sym 4 wave functions are used (Figures 8(b) and 8(c)) some difference in the wavelet coefficients can be observed between the defect-free and the gouged pipe, but it is not so pronounced. But there is a significant difference in wavelet coefficients for the dented pipe. In Figure $8(d)$, where Meyer wave function is used for the CWT, significant difference in wavelet coefficients can be seen even between the defect-free and gouged pipes. For the dented pipe where the Meyer function with a scaling of 16 produces prominent difference between the defect-free pipe and the dented pipe also. The calculated coefficients for the defect-free pipe are much higher than those for gouged and dented pipe. Therefore, Meyer function gives a clear difference between defect-free and defective pipes. 

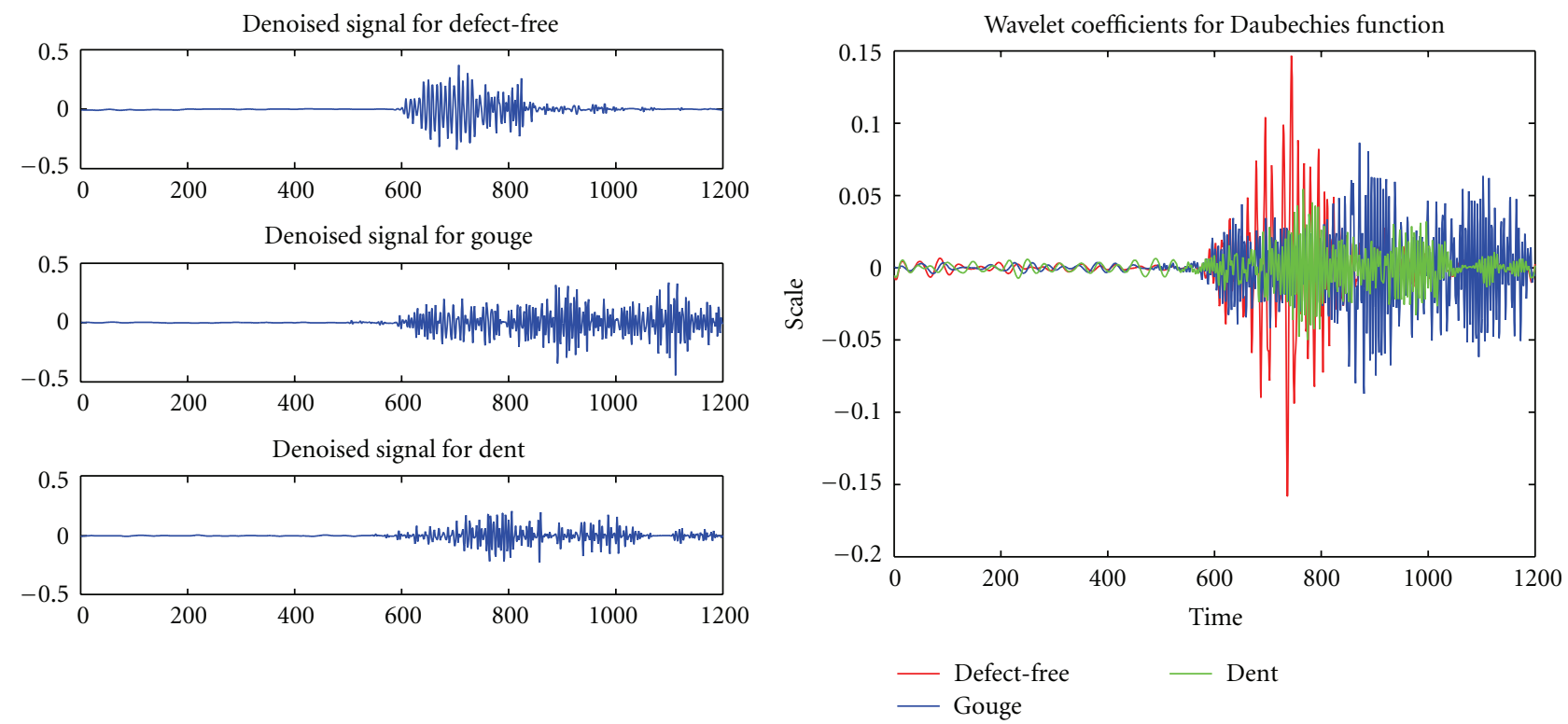

(a)

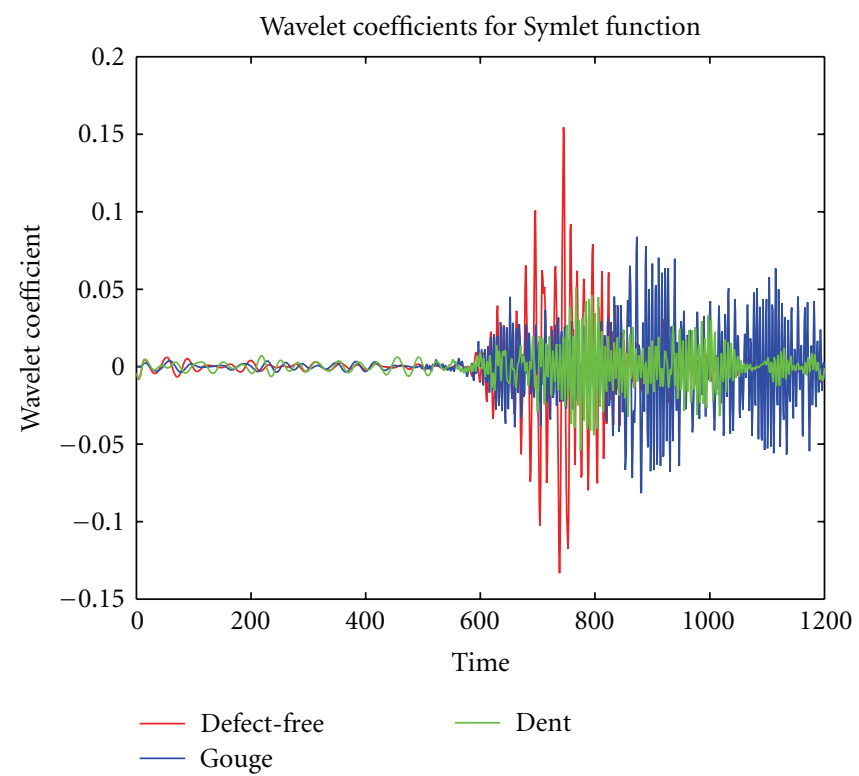

(c)

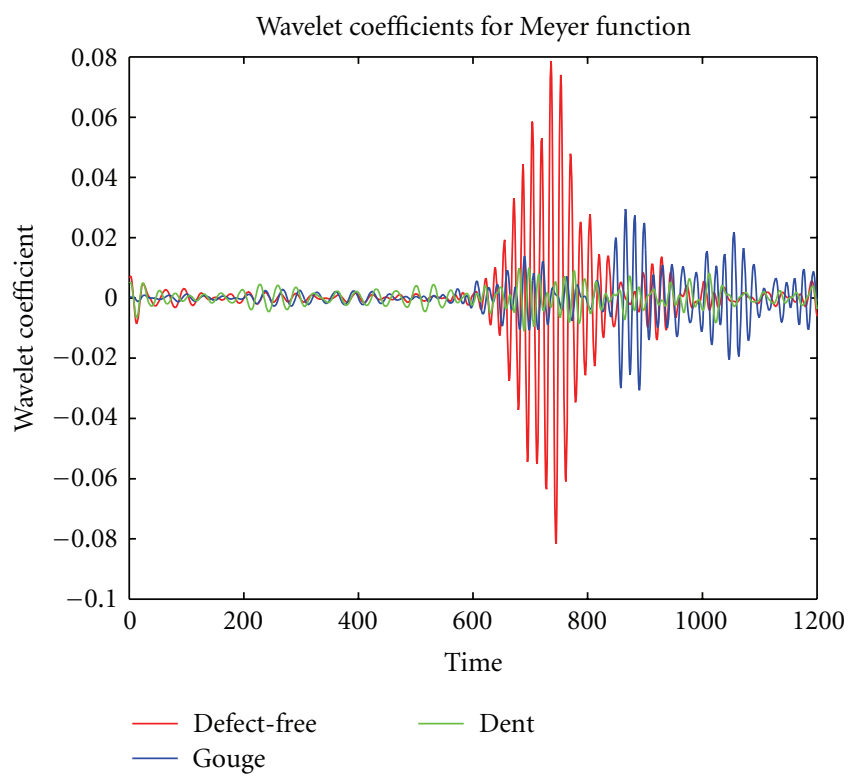

(d)

FIGURE 9: (a) denoised signals for defect-free, gouged, and dent pipes. Continuous wavelet transforms for defect-free, gouged and dented pipes when water flows through the pipes, (b) for Daubechies (db4) function, (c) for Symlet (sym4) function, and (d) for Meyer function.

In other words, Meyer wavelet functions are very sensitive to the defects and produce significant difference between the calculated CWT coefficients for defective and defect-free pipes. It makes Meyer wavelet better suited for structural health monitoring.

Continuous Wavelet Transform When Water Flows through the Pipes. Figure 9(a) shows the denoised signals when the water flows through the pipes. Figures 9(b), 9(c), and 9(d) show continuous wavelet analyses for defect-free and defective pipes using db4, sym4, and Meyer functions, respectively.
As expected, the signal strength for the defect-free pipe is stronger than that of the defective pipes (Figure 9(a)). The difference in signal strength is not apparently visible in Figure 9(a). When CWTs were performed on these signals, the difference can be clearly observed. In Figures $9(\mathrm{~b})$ and 9 (c), where $\mathrm{db} 4$ and sym 4 functions are used respectively for the CWT, the difference in wavelet coefficients for the defectfree and defective pipes can be observed. Among the wave functions that are used for CWT, Meyer function provides best option for finding the difference between the defectfree and the defective pipes (Figure 9(d)). The difference in 

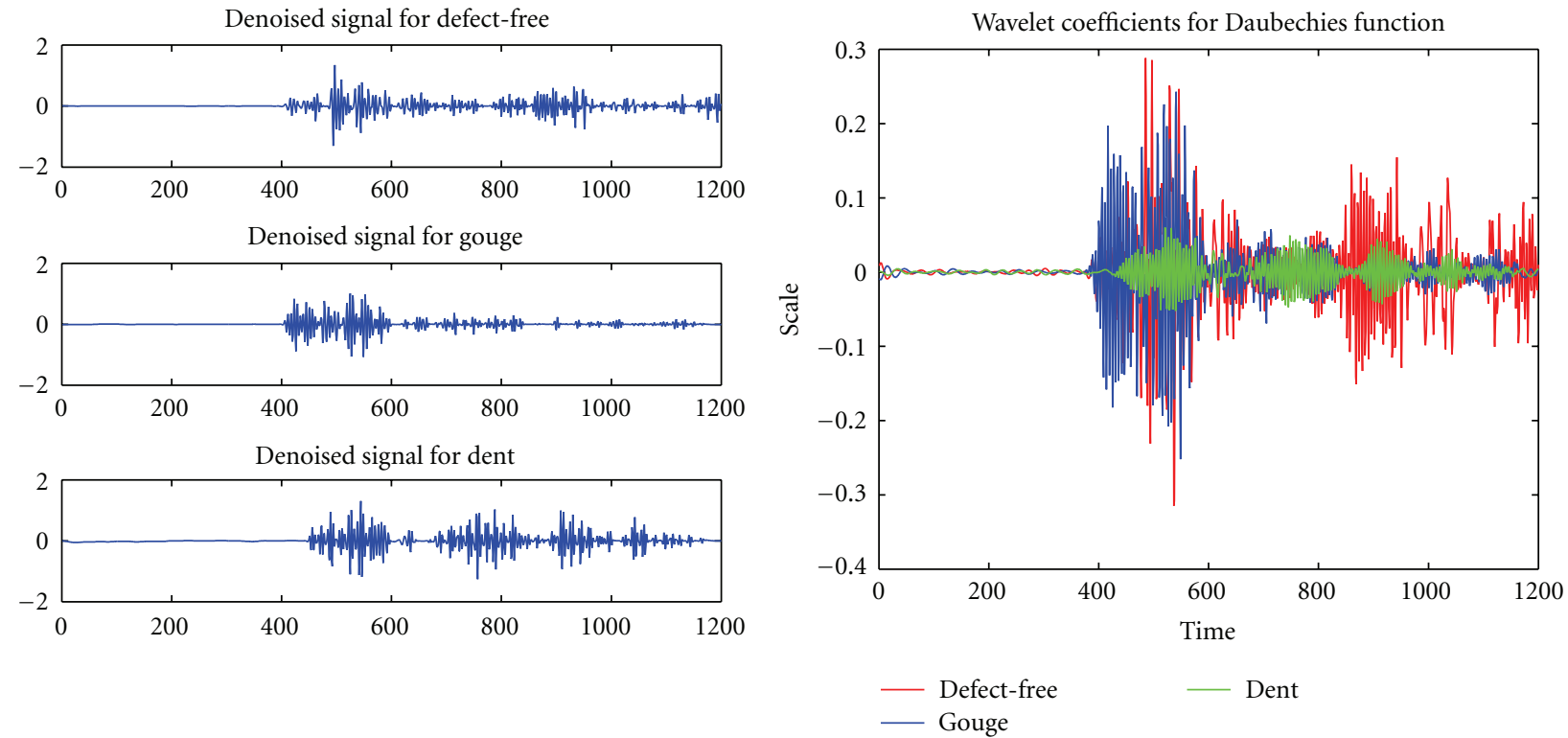

(a)

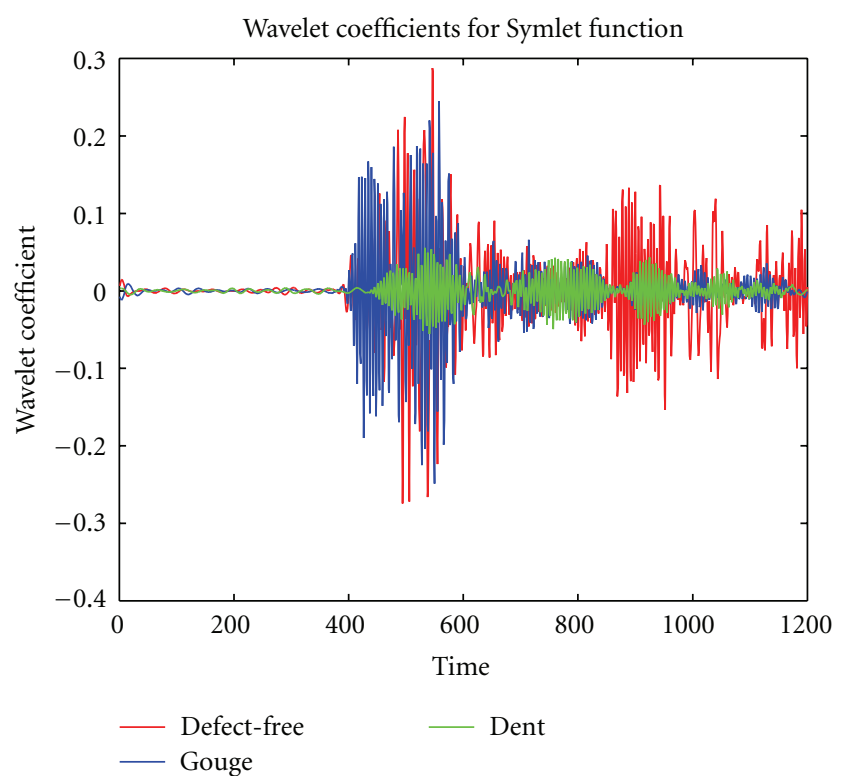

(c)

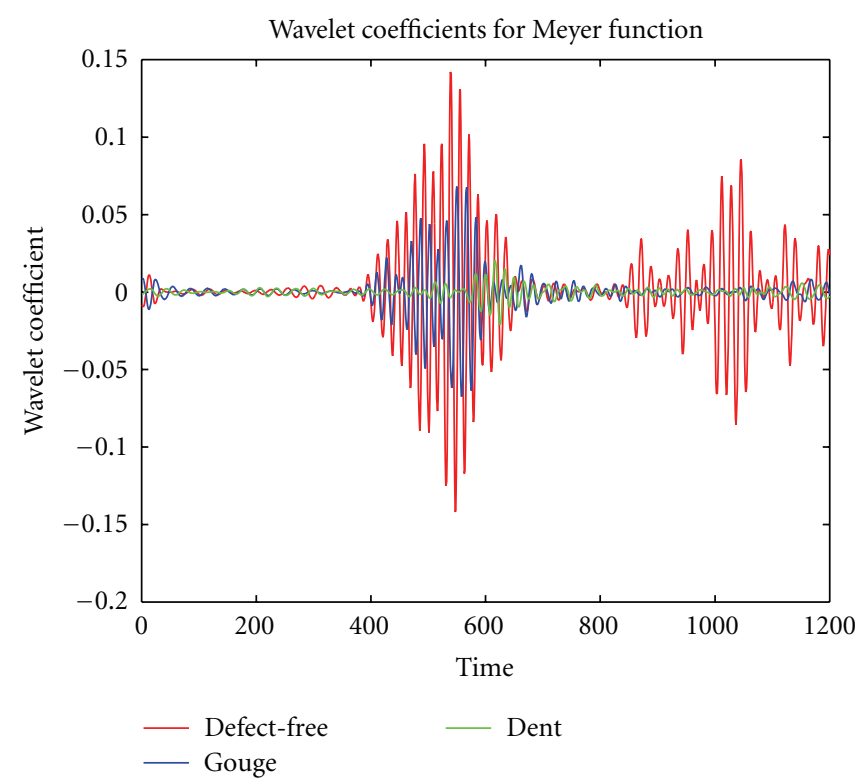

(d)

FIGURE 10: (a) denoised signals for defect-free, gouged, and dent pipes. Continuous wavelet transforms for defect-free, gouged, and dented pipes when pipes are embedded in soil, (b) for Daubechies (db4) function, (c) for Symlet (sym4) function, (d) for Meyer function.

wavelet coefficients for the defect-free and defective pipes, obtained using Meyer function, is significant and can be easily recognized.

Continuous Wavelet Transform When Pipes Are Embedded in Soil. The continuous wavelet transforms for the defectfree and defective pipes embedded in soil are shown in Figures 10(b), 10(c), and 10(d) using db4, sym4, and Meyer functions, respectively. In Figures $10(\mathrm{~b})$ and $10(\mathrm{c})$, where Daubechies (db4) and Symlet (sym4) functions are used respectively, the wavelet coefficients for the defect-free pipe differs considerably from the defective pipes (gouged and dented) for the first patch of propagating modes. It can be also noted that the patterns for the defective pipes (gouged and dented) are similar, and they differ from the pattern shown by the defect-free pipe. The pattern also differs significantly from the traction-free boundary conditions. The signal strength for the defect-free and the gouged pipe is similar, but the strength for the dented pipe is considerably reduced due to the presence of soil (Figure 10(a)). Wavelet coefficients for the defect-free and the gouged pipe are also similar when $\mathrm{db} 4$ and sym 4 functions are used (Figures 10 (b) and $10(\mathrm{c}))$. Significant difference in wavelet coefficients can be observed when Meyer function is used (Figure 10(d)). 
This phenomenon is also observed for the traction-free boundary conditions. Even for the soil embedded condition, where the acoustic signal is expected to loose significant amount of energy, CWT using Meyer's function provides strong evidence of identifying defects in embedded pipes and can easily be distinguished from the defect-free pipe.

\section{Conclusion}

This paper investigates the importance of signal processing techniques in guided wave application for detecting defects in pipes. Two different approaches were investigated and compared. Fourier transforms of experimental signals provide information regarding the propagating modes and help in identifying modes that are sensitive to defects. Continuous wavelet analysis is helpful in identifying defective pipes by comparing wavelet coefficients for pipes under different boundary conditions. This research also investigates which mother wave functions are more effective in distinguishing defective pipes from a defect-free pipe. Depending on the application, any or both approaches could be utilized for successful monitoring of structural integrity of pipes.

\section{Acknowledgment}

This paper was financially supported from the National Science Foundation, Grant no. CMS-9901221 and CMMI0530991, Dr. S. C. Liu (program manager).

\section{References}

[1] D. Z. Gazis, "Three dimensional investigation of propagation of waves in hollow circular cylinders. I. Analytical foundation," Journal of Acoustical Society of America, vol. 31, no. 5, pp. 568$573,1959$.

[2] D. Z. Gazis, "Three dimensional investigation of propagation of waves in hollow circular cylinders. II. Numerical results," Journal of Acoustical Society of America, vol. 31, no. 5, pp. 573578, 1959.

[3] M. G. Silk and K. F. Bainton, "The propagation in metal tubing of ultrasonic wave modes equivalent to Lamb waves," Ultrasonics, vol. 17, no. 1, pp. 11-19, 1979.

[4] M. Brook, T. D. K. Ngoc, and J. Eder, "Ultrasonic inspection of stem generator tubing by chemical guided waves," in Review of Progress in QNDE, D. O. Thomson and D. E. Chimenti, Eds., vol. 9, pp. 243-249, Plenum Press, New York, NY, USA, 1990.

[5] J. L. Rose, J. J. Ditri, A. Pilarski, K. Rajana, and F. Carr, "A guided wave inspection technique for nuclear steam generator tubing," NDT \& E International, vol. 27, no. 6, pp. 307-310, 1994.

[6] J. L. Rose, K. M. Rajana, and F. T. Carr, "Ultrasonic guided wave inspection concepts for steam generator tubing," Materials Evaluation, vol. 52, no. 2, pp. 307-311, 1994.

[7] D. Guo and T. Kundu, "A new sensor for pipe inspection by Lamb waves," Materials Evaluation, vol. 58, no. 8, pp. 991-994, 2000.

[8] D. Guo and T. Kundu, "A new transducer holder mechanism for pipe inspection," Journal of the Acoustical Society of America, vol. 110, no. 1, pp. 303-309, 2001.
[9] W. B. Na, T. Kundu, and M. R. Ehsani, "Ultrasonic guided waves for steel bar concrete interface testing," Materials Evaluation, vol. 60, no. 3, pp. 437-444, 2002.

[10] W. B. Na, T. Kundu, and M. R. Ehsani, "Lamb waves for detecting delamination between steel bars and concrete," Computer-Aided Civil and Infrastructure Engineering, vol. 18, no. 1, pp. 58-63, 2003.

[11] R. Ahmad and T. Kundu, "Influence of water flow through pipe networks for damage detection using guided waves," in Proceedings of the International Symposium on Nondestructive Testing of Materials and Structures (NDTMS '11), Also Presented in the Conference in Istanbul Turkey Istanbul, Turkey, May 2011.

[12] H. Cho, S. Ogawa, and M. Takemoto, "Non-contact laser ultrasonics for detecting subsurface lateral defects," NDT \& E International, vol. 29, no. 5, pp. 301-306, 1996.

[13] O. Rioul and M. Vetterli, "Wavelets and signal processing," IEEE Signal Processing Magazine, vol. 8, no. 4, pp. 14-38, 1991.

[14] A. Abbate, J. Frankel, and P. Das, "Wavelet transform signal processing for dispersion analysis of ultrasonic signals," in Proceedings of the IEEE Ultrasonics Symposium, pp. 751-755, November 1995.

[15] K. Kaya, N. M. Bilgutay, and R. Murthy, "Flaw detection in stainless steel, samples using wavelet decomposition," in Proceedings of the IEEE Ultrasonics Symposium, pp. 1271-1274, November 1994.

[16] R. Ahmad, S. Banerjee, and T. Kundu, "Cylindrical guided waves for damage detection in underground pipes using wavelet transforms," in Health Monitoring and Smart Nondestructive Evaluation of Structural and Biological Systems, T. Kundu, Ed., vol. 6177 of Proceedings of SPIE's 11th Annual International Symposium on NDE for Health Monitoring and Diagnostics, San Diego, Calif, USA, March 2006.

[17] R. Ahmad, S. Banerjee, and T. Kundu, "Underground pipe inspection by guided waves using wavelet analysis," in Health Monitoring and Smart Nondestructive Evaluation of Structural and Biological Systems, T. Kundu, Ed., vol. 6177 of Proceedings of SPIE's 10th Annual International Symposium on NDE for Health Monitoring and Diagnostics, San Diego, Calif, USA, March 2005.

[18] R. Ahmad and T. Kundu, "Application of different continuous wavelet functions on cylindrical guided wave signals for underground pipe inspection," in Proceedings of the 7th International Conference on Urban Earthquake Engineering (7CUEE '10) \& 5th International Conference on Earthquake Engineering (5ICEE '10), Paper no. 08-446, pp. 1217-1223, Tokyo Institute of Technology, Tokyo, Japan, March 2010.

[19] D. Gabor, “Theory of communication," IEEE, vol. 93, no. 3, pp. 429-457, 1947.

[20] M. J. Bastiaans, "Gabor's expansion of a signal into gaussian elementary signals," Proceedings of the IEEE, vol. 68, no. 4, pp. 538-539, 1980.

[21] M. J. Bastiaans, "Sampling theorem for the complex spectrogram, and gabor's expansion of a signal in gaussian elementary signals," Optical Engineering, vol. 20, no. 4, pp. 594-598, 1981.

[22] M. J. Bastiaans, "On the sliding-window representation in digital signal processing," IEEE Transactions on Acoustics, Speech, and Signal Processing, vol. 33, no. 4, pp. 868-873, 1985.

[23] M. Murase and K. Kawashima, "Non-contact evaluation of defects in thin plate with multimode Lamb's wave and wavelet transform," in Proceedings of the ASME International Mechanical Engineering Congress and Exposition (IMECE '02), New Orleans, La, USA, 2002. 
[24] R. Ahmad and T. Kundu, "Guided wave technique to detect defects in pipes using wavelet transform," in Proceedings of the 2nd European Workshop on Structural Health Monitoring, C. Boller and W. J. Staszewski, Eds., pp. 645-652, DEStech Publications, Munich, Germany, July 2004.

[25] R. Ahmad, S. Banerjee, and T. Kundu, "Pipe wall damage detection in buried pipes using guided waves," ASME Journal of Pressure Vessel Technology, vol. 131, no. 1, Article ID 011501, 10 pages, 2009.

[26] D. Velea, F. D. Shields, and J. M. Sabatier, "Elastic wave velocities in partially saturated ottawa sand: experimental results and modeling," Soil Science Society of America Journal, vol. 64, no. 4, pp. 1226-1234, 2000. 

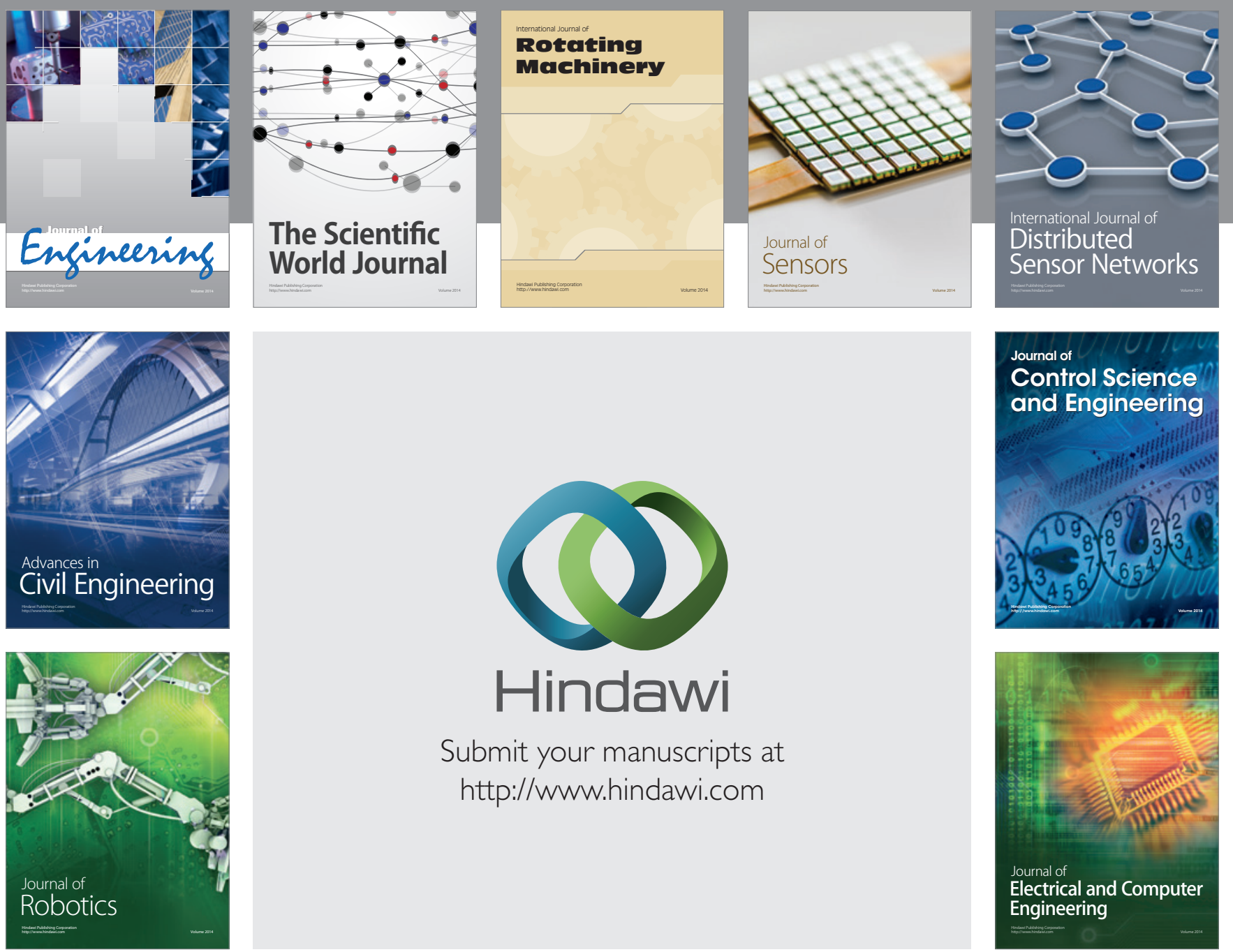

Submit your manuscripts at

http://www.hindawi.com
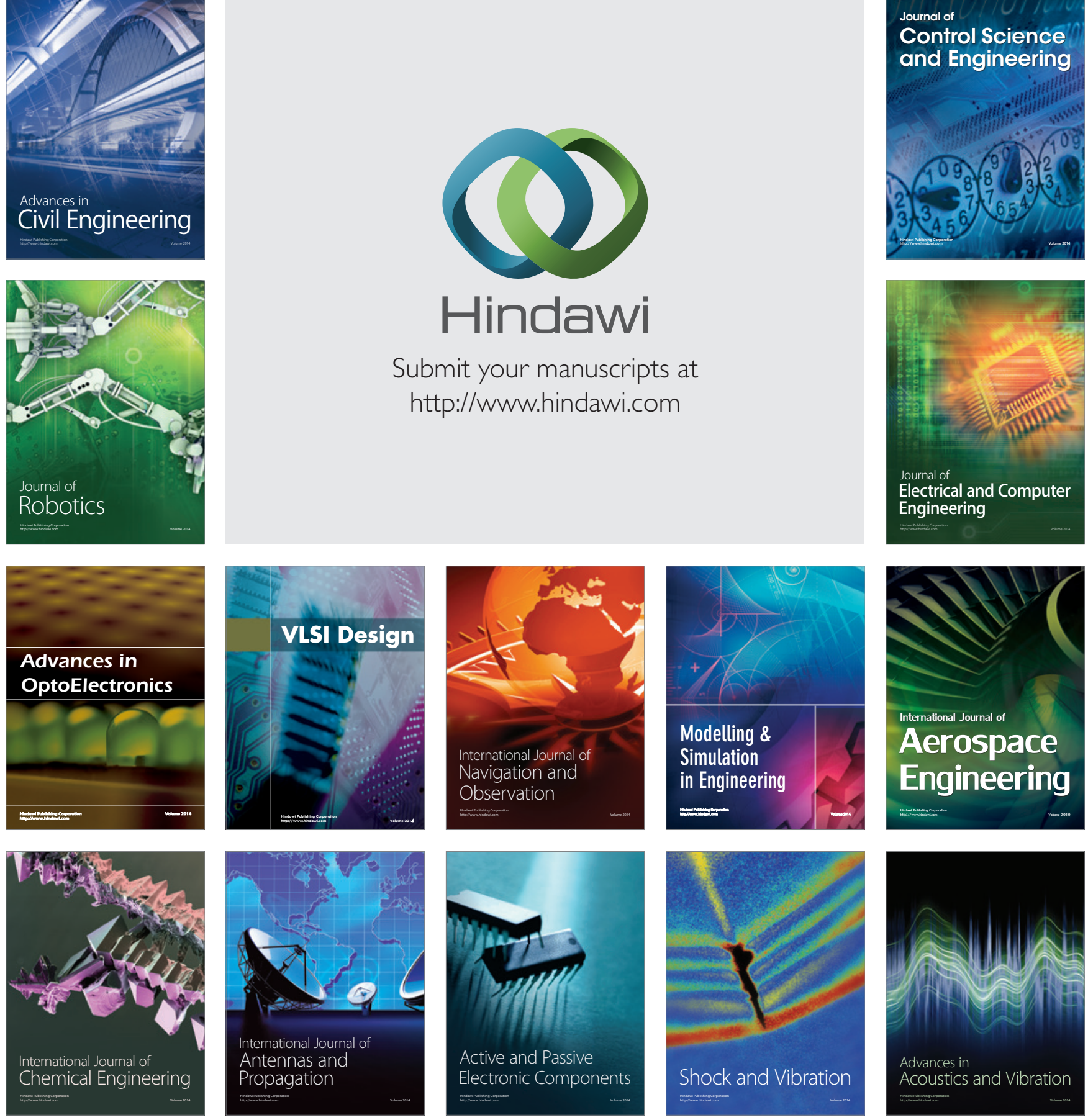